\title{
A Review of Salmon Recovery Strategies for the Columbia River Basin
}

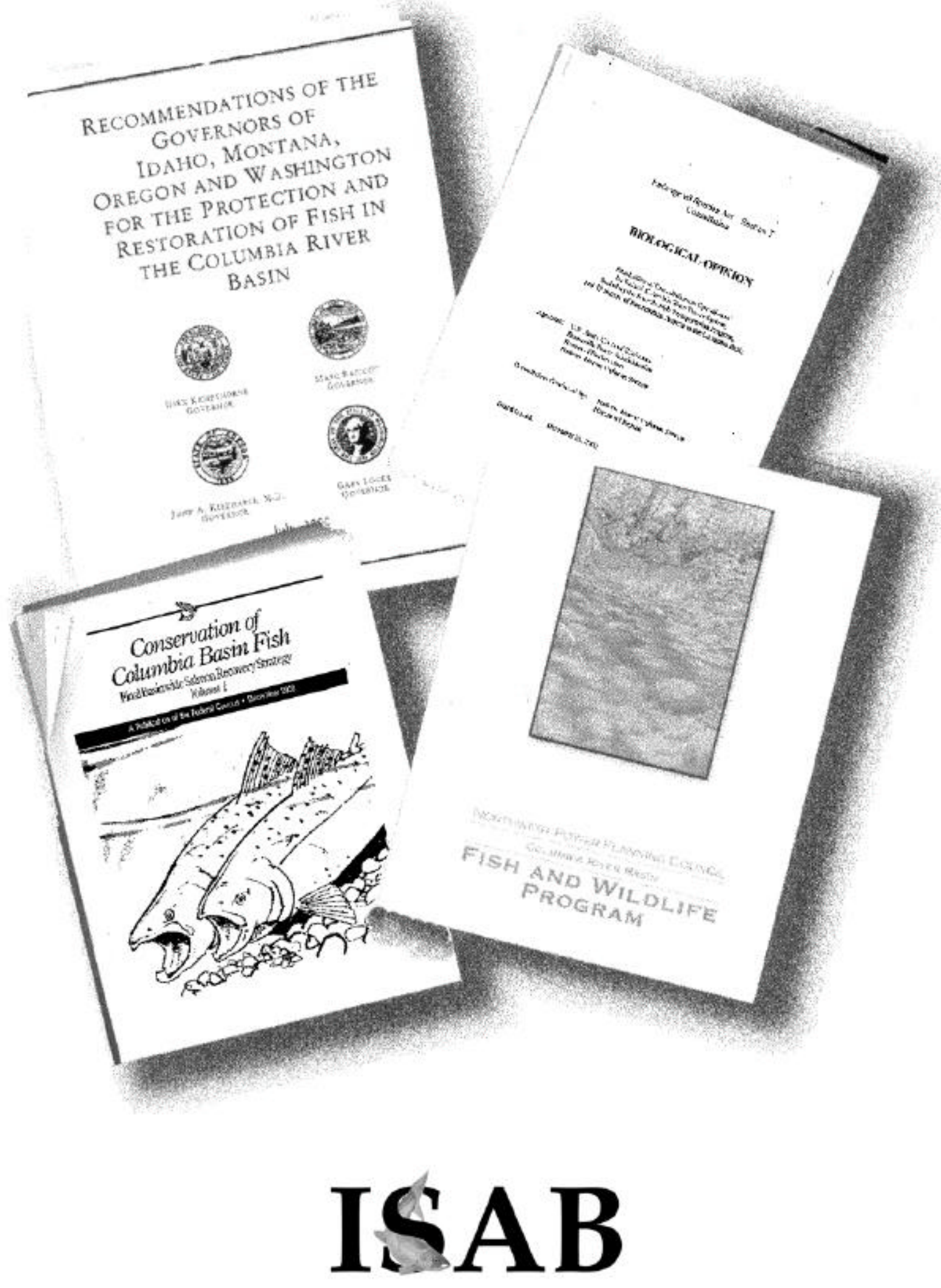




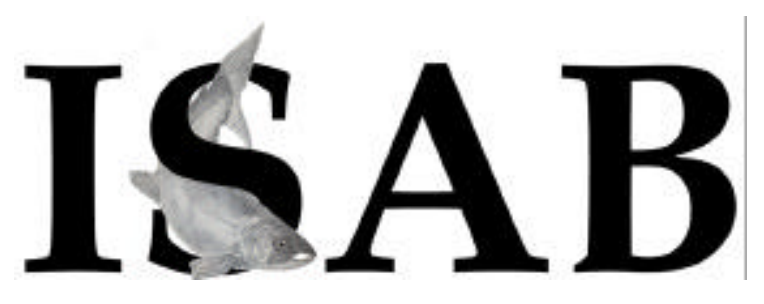

Independent Scientific Advisory Board for the Northwest Power Planning Council and the National Marine Fisheries Service 851 SW $6^{\text {th }}$ Avenue, Suite 1100

Portland, Oregon 97204

ISAB@nwppc.org

\section{A Review of Salmon Recovery Strategies for the Columbia River Basin}

Peter A. Bisson

Charles C. Coutant

Daniel Goodman

Robert Gramling

Dennis Lettenmaier

James Lichatowich

Eric Loudenslager

William Liss

Lyman McDonald

David Philipp

Brian Riddell

ISAB 2001-7

August 22, 2001 


\section{Contents}

EXECUTIVE SUMMARY.............................................................................................................................................................III

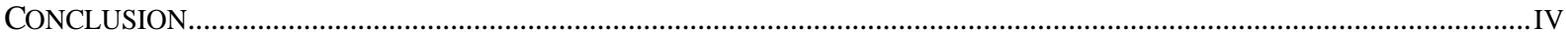

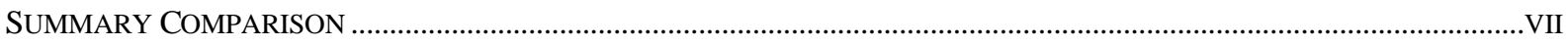

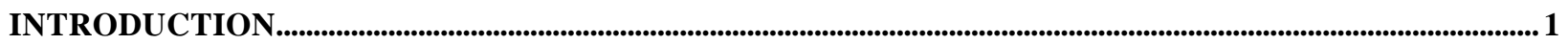

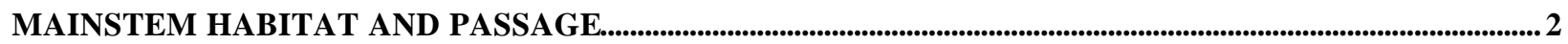

HABITAT

BIOLOGICAL OPINION ……………………………………………………………………………………....

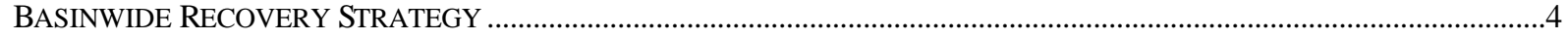

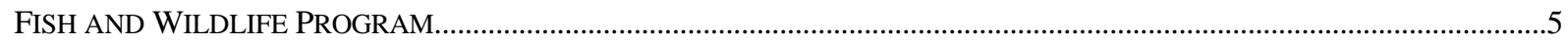

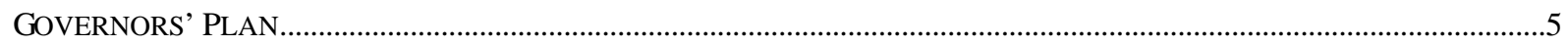

PASSAGE

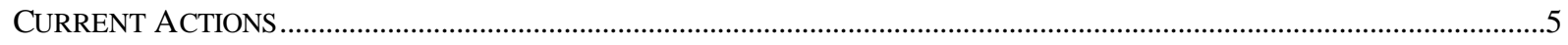

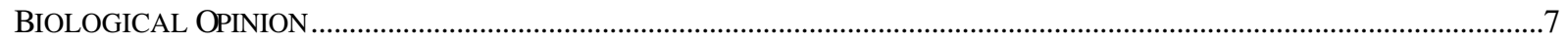

BASINWIDE RECOVERY STRATEGY ………………………………………………………………………...

FISH AND WILDLIFE PROGRAM.....................................................................................................................

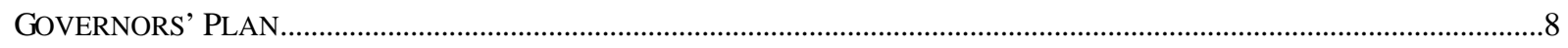

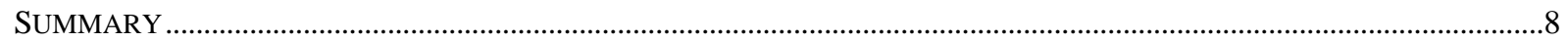

TRIBUTARY HABITAT ....................................................................................................................................................................11

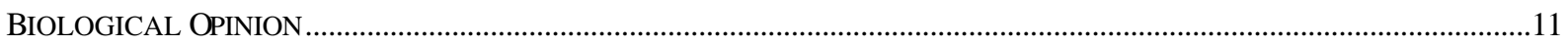

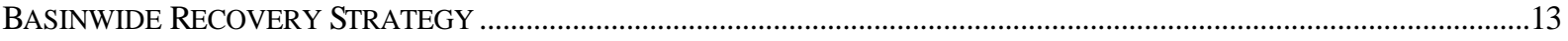

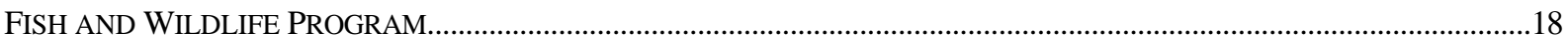

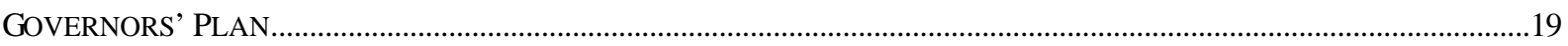

SUMMARY

HATCHERIES ..................................................................................................................................................................................22

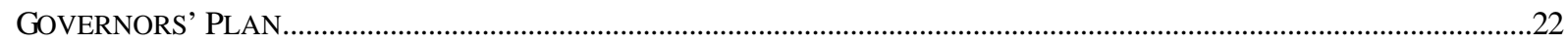

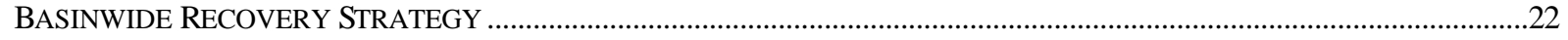

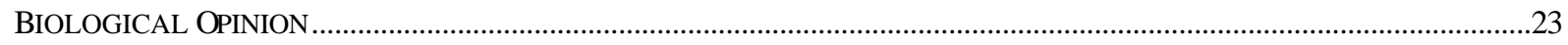

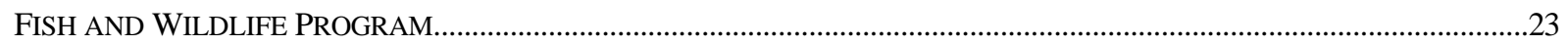

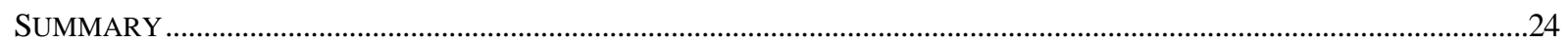

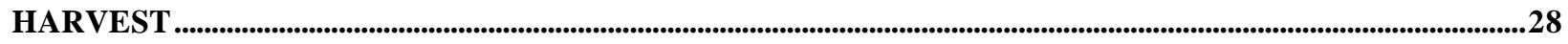

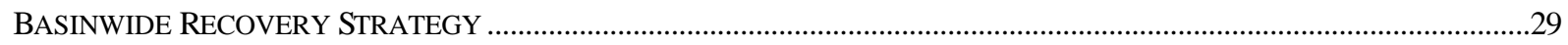

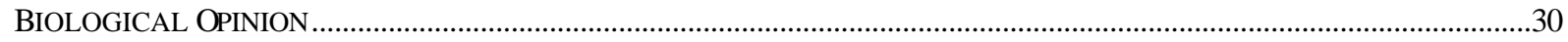

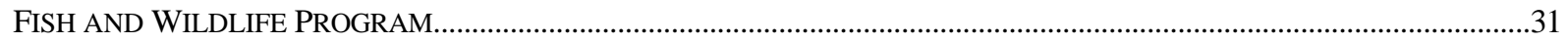

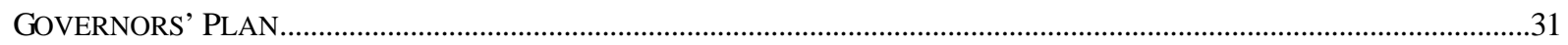

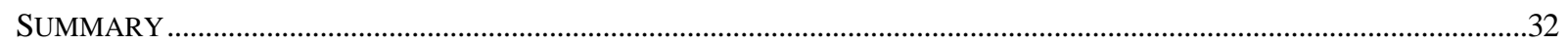

MODELS, MONITORING AND EVALUATION......................................................................................................................35

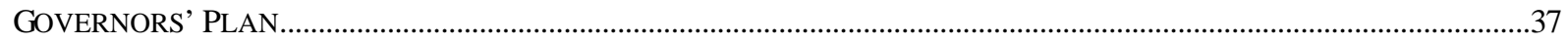

BIOLOGICAL OPINION AND BASINWIDE RECOVERY STRATEGY ……………………...................................................38

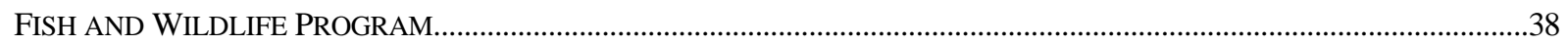

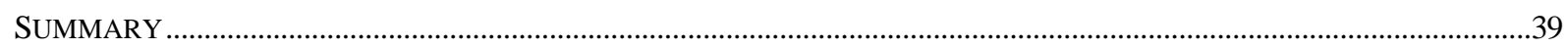




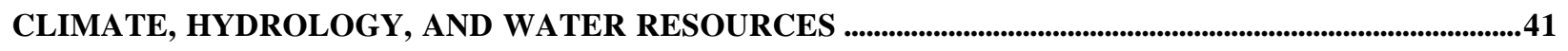

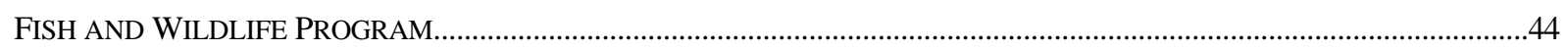

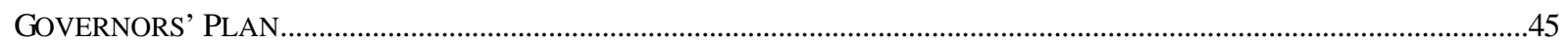

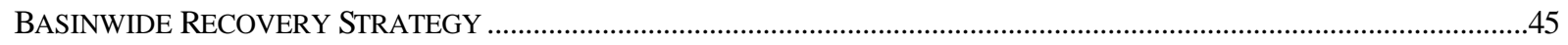

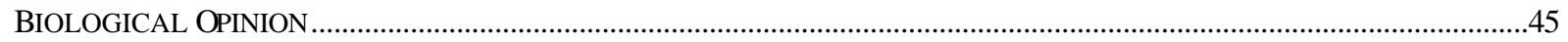

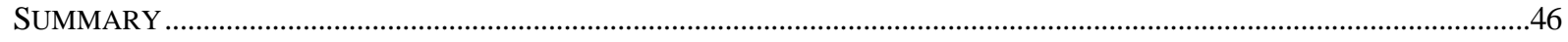

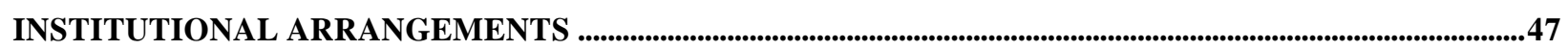

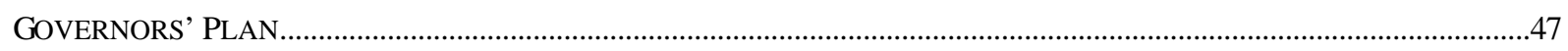

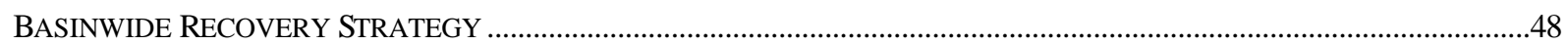

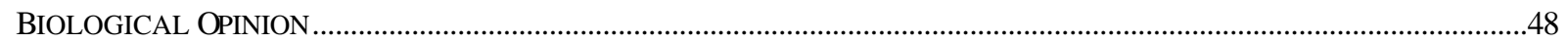

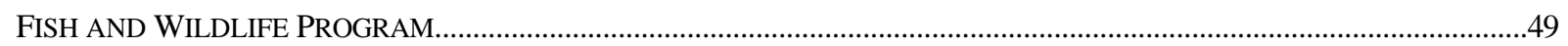

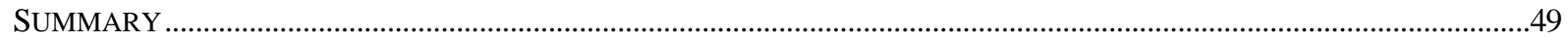

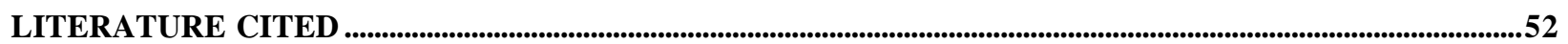




\section{Executive Summary}

Four documents containing strategies for recovering salmon in the Columbia River Basin have been issued recently: the Four Northwest States Governors' Plan, the Northwest Power Planning Council's 2000 Fish and Wildlife Program, the National Marine Fisheries Service 2000 Federal Columbia River Power System Biological Opinion, and the Basinwide Recovery Strategy (All-H Paper). These documents in the aggregate provide a federal and state agency roadmap for salmon recovery in the Columbia River Basin over the next decade. The four papers vary in the extent to which they are explicitly scientific, ranging from the technically detailed BiOp to the more general policy- and process-oriented Governors' Plan. The purpose of this review is not to provide a thorough appraisal of the science contained in each of those documents individually. The question we ask in this review is: "Do these four documents collectively outline salmon recovery strategies that are likely to have a high probability of success?" In attempting to answer this question we considered different elements of the recovery documents, including the familiar "H" categories: Habitat, Harvest, Hatcheries, and Hydroelectric operations. In addition, we examined modeling and monitoring programs, climate and hydrology, and institutional arrangements.

Taken together, the four papers represent a realistic assessment of the problems facing salmon recovery in the Columbia River Basin. There is consistency in many of the kinds of recovery actions proposed in the documents, and the scientific bases for these actions are generally sound. However, the strategies as articulated in the papers usually lack details about how various recovery actions would be implemented (with the possible exception of actions related to mainstem passage) and as a consequence we were uncertain that the actions proposed in them will actually lead to salmon recovery. There is no doubt that the proposed strategies would result in some beneficial results for salmon, which is encouraging, but the status of many of the stocks has become very grave. Recovery documents containing explicit and quantified details are needed so that their sufficiency can be evaluated. We believe the four documents, collectively, fall short of providing this detail.

Two major positive trends distinguish the strategies in these documents from previous recovery plans: 1) they tend to reflect a functional ecosystem approach to salmon recovery, and 2) they make use of quantitative models to assess recovery actions, determine jeopardy, and to evaluate management alternatives. With regard to ecosystem health, the current documents emphasize landscape-based approaches and attempt to direct recovery actions at major components of salmon habitat in the Columbia River Basin. In contrast to previous plans, they address recovery of the estuary, tributary habitat, and features of mainstem habitat beyond water temperature, flow, and gas saturation. The documents propose a watershed planning process that tailors recovery actions to natural biophysical conditions of subbasins and provinces. The documents also acknowledge the importance of using natural conditions as a guide for restoration.

With regard to the use of models, the recovery documents place more reliance on mathematical simulation than previous plans. Extinction risk models developed by NMFS were used to assess jeopardy in the Biological Opinion, and the Cumulative Risk Initiative (CRI) model was used to assess impacts at different stages of the life cycle and to establish reasonable recovery alternatives. The Salmonid Watershed Assessment Model (SWAM), another NMFS model, is 
intended for use in developing recovery actions for tributary habitat. The Northwest Power Planning Council uses the Ecosystem Diagnosis and Treatment (EDT) model to evaluate recovery strategies at the provincial and subbasin scales.

\section{Conclusion}

The ISAB believes the overall answer to the question of whether the four documents will lead collectively to salmon recovery actions that have a high chance of succeeding is probably no, although we do not wish to diminish the scientifically sound recommendations contained in each of them. We reach this conclusion for reasons that hinge on data gaps, conceptual gaps, program integration, and implementation of recovery actions. While we feel the strategies outlined in the documents offer some real advances in the science of salmon recovery, particularly with adoption of an ecosystem perspective and better use of models, important scientific data necessary to resolve critical uncertainties still have not been obtained. Shortcomings in program integration and implementation, inadequately addressed in the documents, are particularly troublesome because of the lack of clear institutional arrangements to carry the programs out. While implementation is not strictly a science issue, failure to clearly specify how recovery strategies would be achieved is a problem these documents share with many previous Columbia River Basin salmon plans.

Data Gaps. One of the fundamental shortcomings of salmon recovery planning in the Columbia River Basin has been the failure of management organizations to establish historical population and environmental databases. As a result, current recovery efforts rest on geographically limited data of varying quality and applicability. If reliable data collection protocols are established, future comparisons to current data will have difficulty discerning whether population trends are due to real changes caused by management actions, changes in the environment unrelated to management actions, or just reflect the inaccuracy of historical estimates. This problem did not originate with the present generation of recovery documents, and in fact reasonable improvements in plans for future monitoring and evaluation are specified in some of them. This is a situation, perhaps unfair, in which it will be difficult to assess the effects of proposed management actions, and know whether to continue or change them, because baseline data are inadequate. To assume that monitoring strategies can be implemented in time to assess real changes in the 5-8 year time frame proposed in the Biological Opinion is unrealistic.

Conceptual Gaps. The salmon recovery documents too often fail to address important issues in a really meaningful way. Several examples are noteworthy.

$>$ Hatchery Reform. While all of the documents acknowledge the need for hatchery reform for a variety of reasons, it is not clear from them what they mean by hatchery reform, or how it should be implemented. There is a significant gap between concept and application. The four documents do not map a detailed strategy for reducing risks of harmful interactions between wild and hatchery fish, but instead defer to the Artificial Production Review (NW Power Planning Council Document 1999-15), which suffers from a similar lack of detail. The documents assume that supplementation will succeed in rebuilding populations and that artificial production will mitigate habitat loss - two frequent but unverified assumptions. 
$>$ Climate and Demographic Trends. While the documents acknowledge that environmental variation must be taken into account, they do not appear to be sensitive to the types of environmental variations that are systematic, that is, constitute probable trends. Two of these seem especially relevant to salmon recovery.

1. Climate Change. If current forecasts of climate change are correct, it is quite possible that hydrologic regimes in the region will change, probably with negative implications for recovery efforts. The documents appear to assume that the Columbia River Basin will remain within the range of climatic variations observed over the last century. They do not specify alternative actions if this assumption proves to be incorrect.

2. Human Demographic Changes. If current forecasts of human demographic trends are correct, increasing stress will be put on the basin's natural resources and perhaps even more importantly, on the power demands of the hydroelectric system. This trend would have implications for any recovery program. We found few if any attempts to reconcile salmon restoration efforts with regional strategies for future population growth and development.

$>$ Tributary Habitat. The documents tend to lack a strong conceptual foundation for determining desired habitat conditions in a watershed, estimating the productive capacity of watersheds for salmonids, and evaluating restoration alternatives. Natural disturbances, usually viewed as undesirable, but in reality important for long-term salmon habitat creation and maintenance, are acknowledged in some of the documents. However, there is little indication of how managing the effects of natural disturbances such as wildfires and floods would figure in restoration programs.

$>$ Harvest. The documents do not provide the conceptual basis for establishing escapement goals for each production unit, prediction of adult returns, and plans for how harvest levels factor into conservation and recovery goals. All of the documents support selective fisheries based on retention of marked fish, but there are potential conflicts between such fisheries and the region's coded wire tag program that has been fundamental to the management and conservation of wild stocks.

Integration. To be truly effective, recovery actions must be integrated in a way that strategically addresses problems occurring throughout the salmon life cycle. Plans can only be as effective as the weakest link in the chain of management decisions that influence life stage survival. Too often the four documents did not adequately consider interactions between policies that affect different salmon life stages in the context of the various Hs. For example, the potential interaction between habitat rehabilitation projects and population supplementation was not adequately addressed, nor was the potential effect of harvest on nutrient levels in salmon nursery areas discussed.

Implementation. In considering the four documents together, we found problems associated with implementing the proposed actions most troubling. There were several very difficult issues.

$>$ The level of institutional cooperation between state agencies, tribes, federal agencies, and private landowners needed to achieve salmon recovery in the Columbia River Basin is unprecedented. Fully implementing the proposed actions would require a level of cooperation that has never before been achieved, and the documents do not explain how this cooperation would be pursued. In particular, the documents reject mainstem dam breaching 
in favor of aggressive tributary habitat restoration, but how coordination will occur between public, private, and tribal land managers to provide habitat improvement is inadequately addressed.

$>$ Details of recovery actions and implementation strategies are often lacking. In many instances the four documents present "plans to do planning". The documents assume that details will be worked out sometime in the future in spite of the fact that it has not been possible to work them out in the past.

$>$ The documents do not provide strategies for dealing effectively with limited knowledge and high uncertainty in an adaptive management context. Typical management responses in the past have been to postpone potential recovery actions pending future scientific findings and actual population responses. Not acting is a decision and places the burden of proof on organizations attempting to conserve the resource (i.e., to demonstrate that a significant impact would be likely). Developing explicit strategies for dealing with high levels of uncertainty is a painful but necessary process.

$>$ None of the documents adequately explain the procedures and circumstances that would trigger a departure from their recommendations. As this report is being prepared, the Columbia River Basin is experiencing the most severe drought conditions since 1977 and many of the action items in the BiOp pertaining to operation of the hydrosystem have been recently modified to accommodate the need for electrical power production. However, the documents do not describe how or when such extraordinary circumstances might cause a departure from stated restoration strategies. Nowhere are environmental thresholds identified that would lead to significant changes in management actions, including abandonment of existing plans. Such a lack of specificity underscores our concern that these four documents may not have the collective strength to serve as a robust blueprint for salmon recovery in the Columbia River Basin.

Recovering salmon populations in the Columbia River Basin is an enormous undertaking, and the four documents represent a serious effort by state and federal agencies to develop a coordinated regional salmon strategy. Many of the scientific underpinnings of the documents are consistent with current ecological beliefs. The ISAB found relatively few instances in which they were clearly based on outdated science. Many passages in the documents appeared to be works-in-progress in which details, hopefully, would eventually emerge from subbasin assessments, experimental management, operational reforms, and research and monitoring. These details, of course, ultimately determine the documents' successes or failures. We hope some of the ideas and suggestions in this review will be helpful to scientists and policy makers as recovery actions continue to evolve and monitoring programs are put in place. 


\section{Summary Comparison}

The ISAB approached its task by asking questions of each document relative to factors important in salmon recovery, i.e., mainstem habitat, tributary habitat, hatcheries, harvest, monitoring, climate changes, and institutional arrangements. These questions are included in the following table as a way of framing our assessment of the plans' collective likelihood of success. Additional details are found in appropriate sections of this report.

Table 1. Comparison of the four salmon recovery reports by topic area.

1. Do the documents in aggregate represent an adequate response to the problem? Do the documents describe a course of action that is likely to achieve regional goals such as ESA delisting, harvestable fish, and sustainable ecosystems?

\section{$\underline{\text { Mainstem Habitat and Passage }}$}

The recovery documents recognize the issues of mainstem habitat (i.e., ecosystem structure and function) far more than did any earlier plans. The documents in aggregate are a significant response to the mainstem habitat and passage problem. Some aspects of the strategies represent a major evolution in thinking, while other proposed actions represent a continuation of previous recovery programs. The Governors' Plan is essentially a statement of social (political) support for restoration activities. Next in level of detail is the Fish and Wildlife Program, which at this stage in its development is a statement of principles, goals, and general strategies. The Basinwide Recovery Strategy further outlines strategies, which are restated in a different format in the Biological Opinion. The course of action has a strong life cycle and ecological orientation, which represents a more realistic strategy than had been expressed previously.

The general optimism over the new plans for the mainstem depends, of course, on the level of implementation. The old plans had some action items and measures that were ecologically oriented as well but the action items were often ignored in practice. The action items needed now for ecological restoration are, for the most part, still largely feasibility studies. For restoration efforts to succeed these studies must be carried out and the proposed actions deemed feasible before full-scale implementation. In contrast, the traditional actions (e.g., flow specification, screens, transportation) have a momentum of past history that makes it more likely that they will be continued and even expanded incrementally, perhaps to the detriment of newer, ecologically oriented initiatives. For example, the artificial transportation program for smolt migration is still advocated in the Biological Opinion, despite a significant trend toward adopting an overall recovery strategy that moves toward natural ecological processes (either directly or through engineering designs that mimic nature), a direction the Independent Scientific Group termed moving toward more normative conditions. 


\section{$\underline{\text { Tributary Habitat }}$}

The Governors' Plan and the Fish and Wildlife Program outline conceptual or procedural approaches to tributary habitat restoration but do not explicitly consider limiting factors or habitat performance measures. The BiOp and Basinwide Recovery Strategy contain a much more substantive discussion of tributary habitat. The process for recovering tributary habitat relies heavily on a combination of modeling, interagency cooperation, and landscape assessments at the subbasin level. Real progress toward meeting regional goals could be possible if the EDT modeling effort of NWPPC is able to generate useful first-level subbasin assessments; if action agencies are able to agree upon robust and ecologically meaningful sets of performance standards; if there is adequate habitat and fish population monitoring; and if participating organizations can learn from past restoration failures and new scientific information. But a breakdown in any of these steps would significantly delay implementation of landscape-based restoration. Given current institutional programs, it is doubtful that monitoring will provide quantitative answers about the success of many tributary habitat restoration projects in meeting the goals of the BiOp within 10 years.

\section{$\underline{\text { Hatcheries }}$}

The ISAB believes the answer to both questions is no. Little evidence is provided for anticipating that the hatchery reform measures proposed in the Artificial Production Review (APR) will improve salmon recovery. The BiOp and Basinwide Recovery Strategy do not determine in a quantitative way the extent to which hatchery programs impact listed species. Since the magnitude of the impacts is unknown, any benefits from reducing the impacts of hatchery fish on native stocks are also unknown. Similarly, evaluations of existing supplementation and captive rearing programs provided in the documents are inadequate to determine if these activities can make significant contributions to recovery of listed species.

\section{$\underline{\text { Harvest }}$}

The documents do not directly address harvest but rather assume that the changes in harvest management that have evolved over the past 10-20 years will continue, depending on the fishery and status of stocks. These changes include substantial reductions in the total exploitation rates on naturally spawning salmonid populations, fishing regimes responsive to changes in abundance, and management of total fishing mortality (i.e., catch plus associated incidental mortality). In general, the agencies preparing these documents are not responsible for these changes and do not regulate fisheries, with the notable exception of the NMFS or USFWS responsibility for jeopardy evaluations on ESA-listed fish. Consequently, authors of the documents cannot guarantee a continuation of harvest rate reductions assumed in their assessments, although if the productivity of the natural populations remains depressed, rates will likely increase. Each document supports the expansion of selective fishing techniques and, in particular, the development of mass-mark selective fisheries. The implicit assumption in massmark selective fisheries is that the total mortality of naturally produced salmonids associated with catch-and-release selective fisheries is less than the mortality in complete retention fisheries, and that the resulting harvest rate of wild stocks will be sustainable. Intuitively this assumption seems obvious, but it may not be. 
A related concern is the development of mass-mark selective fisheries and their potential impact on the Coded Wire Tag (CWT) program. The CWT program is essential to the estimation of total exploitation rates in fisheries by age and stock (natural and hatchery) and is the only means to measure these parameters. Yet continuation of the current rates of exploitation are the performance standards stated in the Basinwide Recovery Strategy. At this time, we are uncertain whether the viability of the CWT program can be maintained if mass-mark selective fisheries are implemented. The loss of information may be unacceptable to other fishery management processes outside of the Columbia River system. Obligations of the Pacific Salmon Treaty require that each country assess the aggregate exploitation rates over all fisheries and to ensure that this aggregate value is less than a maximum value stated in the Chinook Annex. It is the responsibility of each country to meet this requirement before additional harvest restraints could be requested through the Pacific Salmon Commission.

\section{$\underline{\text { Models, Monitoring, and Evaluation }}$}

The documents do not present sufficient detail with respect to monitoring. They are correct in identifying the need for a successful long-term monitoring program, but only a general outline for monitoring is given. Success depends on details of statistical design, and successful implementation will require the high level of cooperation called for, including give and take by all concerned: state and federal agencies, tribes, and private organizations. The recovery documents do not contain enough details for us to have confidence in the adequacy of monitoring plans.

\section{Climate, Hydrology, and Water Resources}

The documents do not adequately consider the interactions of climate and hydrology as they affect the natural and managed river system. Specifically, the importance of climatic variability from seasonal to interannual time scales in response to global climatic connections (felt primarily through variations in sea surface temperature in the tropics, which also affect ocean survival) is ignored. The documents also ignore the implications of long-term climate change, which is likely to result in permanent changes in the patterns of winter snow accumulation throughout the basin, and consequently the timing and amount of seasonal discharge. Implications for management of the reservoir system with an earlier spring freshet and reduced summer flows are likewise overlooked.

\section{$\underline{\text { Institutional Arrangements }}$}

Based on the contents of the reports, the ISAB believes the answer to both questions is probably no. While the documents attempt to define the problems and identify desirable future conditions, and in some cases suggest measures to determine whether those conditions have been attained, they provide little guidance on how institutions can function more effectively to promote ecosystem recovery. With the exception of the Governors' Plan there is no treatment in any of the documents of the probable trends in human population and economic growth and of the impacts these trends could have on the Columbia River Basin. In addition, there is almost no discussion of the complex institutional structure existing within the Columbia River Basin nor of 
the ways elements of that structure might facilitate, impede, or otherwise influence planning processes and implementation of recovery actions.

\section{Do the documents in aggregate represent a change in the status quo or a continuation of past} efforts?

\section{Mainstem Habitat and Passage}

The documents represent a significant change in the status quo. The current principles, justifications, and the specific recovery actions are strongly ecological and life cycle based, in contrast to technologically justified engineering fixes stressed earlier (e.g., specified flows and dam modifications). Many past efforts are also continued, but with a decidedly more ecological and life-cycle emphasis, e.g., an emphasis on more ecologically compatible surface bypasses and weirs for fish passage at dams rather than artificial screening systems. However, there are still vestiges of obsolete salmon biology in the Biological Opinion. For example, in section 6.2.9 it is stated that habitat features such as riparian vegetation, food, and rearing space are not needed by certain stocks in the mainstem. Such inaccurate statements have led to further simplification of the mainstem ecosystem based on a narrow view of protecting a few prominent stocks, when a return to habitat complexity is needed for the entire assemblage of diverse stocks and species.

\section{$\underline{\text { Tributary Habitat }}$}

The greatest difference between the approaches outlined in the four documents and past tributary habitat restoration efforts is that these documents place much more emphasis on formulating landscape-based recovery strategies. This means that restoration projects will in principle be chosen on the basis of their overall contribution to recovery within the context of salmon life history needs (preferred habitats, seasonal movements) and the extent of habitat alteration (locations of habitat bottlenecks or high quality refugia) within the subbasin of interest. Whether implementation of tributary habitat restoration efforts under the strategies will represent a continuation of past programs or a real change in the status quo will depend on their ability to take advantage of recent improvements in knowledge of salmon life history and watershed processes. Agencies will have to achieve a level of communication and coordination that is unprecedented for such a large area, particularly because their mandates may occasionally generate actions that are contradictory. Habitat performance standards will need to transcend water quality hazard thresholds, the traditional approach, and take dynamic watershed processes into account. Subbasin plans will need to demonstrate a linkage between programs that show a concern for the entire freshwater life cycle of salmon rather than simply a collection of individual restoration projects.

\section{$\underline{\text { Hatcheries }}$}

The documents represent a continuation and evolution of past efforts. With regard to artificial production this may not be an entirely unavoidable or undesirable approach, at least in the short term. If an acceptable artificial production program is possible, designing or creating it is likely to involve occasional progress with many mistakes. Similarly, abandoning or substantially 
curtailing artificial production, concluding that it is a failure, will only happen once stakeholders have exhausted their efforts to make it succeed.

\section{$\underline{\text { Harvest }}$}

The documents propose both a continuation of the status quo and new initiatives. The general assumption that reductions in harvest impacts will be maintained is a continuation of past patterns. The development of more selective fishing techniques is an emerging idea, and is a significant change from the status quo. This change, however, has a number of concerns associated with it that were not fully discussed in the four documents.

\section{$\underline{\text { Models, Monitoring, and Evaluation }}$}

With respect to harvest, hatcheries and hydropower, the strategies in the documents represent a continuation and evolution of past efforts in monitoring, evaluation and modeling. More emphasis is placed on monitoring and evaluation of management actions for improvement of tributary habitat for anadromous species and on the effects of hatchery produced fish on naturally spawning stocks. Also, more emphasis is being placed on monitoring reproductive performance of wild stocks throughout the Columbia River Basin, i.e., monitoring and evaluation of "fish coming in and fish going out" of natural production areas.

\section{Climate, Hydrology, and Water Resources}

With regard to this topic the four documents do not present a meaningful change in the status quo. The inherent assumption in them is that the future will resemble the past. This assumption, which underlies essentially all water resource design and management in the Columbia River Basin and elsewhere, is now being called into question.

\section{$\underline{\text { Institutional Arrangements }}$}

The strategies in the documents represent primarily a continuation and evolution of past efforts. While agency plans have grown in detail and complexity, the primary focus is on desired future conditions, largely ignoring the institutional arrangements that have led to the current situation. Proposed recovery strategies, for the most part, rest on the assumption that top-down planning, informed by science, can restore productive salmon ecosystems. The Governors' Report challenges this assumption, but presents little evidence that local planning will lead to a dramatic change in the status quo resulting in more effective salmon recovery actions.

\section{Do the documents provide a consistent course of action?}

\section{$\underline{\text { Mainstem Habitat and Passage }}$}

Recognizing that each report has its own specific objective, audience, and level of detail, the documents seem quite consistent about protecting and restoring habitat values in the mainstem and providing fish passage opportunities that better match natural migration needs. The 
declaration of a flow emergency in 2001 that vacated the terms of the Biological Opinion and other recovery plans, however, raises important issues. What criteria are used to determine when fish recovery actions must give way to the need for hydropower? Some unwritten criteria were clearly exceeded in 2001. It would be useful to know what these criteria were, or alternatively, to see the plans establish a process for creating criteria explicitly for use in the future. The documents in aggregate are silent on such emergency criteria from the fish recovery perspective.

\section{$\underline{\text { Tributary Habitat }}$}

The BiOp, Basinwide Recovery Strategy, and Fish and Wildlife Program outline a consistent course of action for tributary habitat restoration, and all three documents utilize independent scientific peer review (e.g., TRTs, ISAB, ISRP, RSRP) to provide external quality checks. The Governors' Plan appears to be least consistent with the other documents. Although the section on habitat in the Governors' Plan is brief, it is clear that it endorses restoration efforts designed by local organizations (watershed councils, city and county authorities) as opposed to efforts designed by large federal agencies. The Governors' Plan, however, makes no mention of scientific peer review of local plans.

\section{$\underline{\text { Hatcheries }}$}

The answer to this question is yes, but the documents present a consistently inadequate course of action. For example, even though all four documents recognize a need for hatchery reform, none of them gives sufficient details describing specific reforms or plans of how to implement them.

\section{$\underline{\text { Harvest }}$}

In general, there is a high degree of concordance among the four documents. They include strategies for maintaining conservative harvest levels and honoring treaty obligations.

\section{$\underline{\text { Models, Monitoring, and Evaluation }}$}

Basically, the four documents are consistent in their call for aggressive monitoring and evaluation of management actions aimed toward recovery of threatened or endangered salmonid populations within ESUs and to support a sufficient abundance of anadromous salmonids to allow increased harvest. The ISAB suggests that Columbia River Basin managers (1) start with the present monitoring of harvest and the hydropower system, and add the first two tiers of the hierarchical plan identified in the BiOp and Basinwide Recovery Strategy for threatened and endangered fish species (including resident fishes) and their potential habitat, (2) continue the Council's call for effectiveness monitoring of projects in the Fish and Wildlife Program consistent with Tier 3 monitoring in the BiOp and Basinwide Recovery Strategy, (3) implement the recommendations for monitoring of hatcheries called for in the ISAB review of performance standards for artificial production, and (4) re-evaluate the harvest and hydropower monitoring programs. 


\section{Climate, Hydrology, and Water Resources}

The four documents are consistent in that they assume that the future will resemble the past. All of the documents deal, in one way or another, with flow and flow augmentation issues in the Columbia River mainstem and major tributaries. Hence, even if not explicitly recognized, the use of historical observations to determine effects of altered operations implies an assumption about climate. None of the documents explicitly considers the implications of proposed changes on hydrosystem performance, particularly in low water years that are the basis for the critical period planning approaches used to determine firm power.

\section{$\underline{\text { Institutional Arrangements }}$}

The four documents do not provide a consistent course of action with respect to institutional arrangements. Each of the documents has different goals and was inspired by somewhat different problems. The level of planning, key participants in identifying restoration priorities, and responsibility for monitoring and evaluation differs among the documents.

\section{Are linkages among strategies for dealing with the 4 H's adequately identified?}

\section{$\underline{\text { Mainstem Habitat and Passage }}$}

For the most part, there was little in the four documents that described how management of mainstem salmon habitat and fish passage issues would be adjusted for changes in management actions with respect to the other Hs. Cross-linking of items in subsequent drafts of the reports could be useful for coordination within the Columbia River Basin. Thus, implementation of a certain mainstem-related Action from the Biological Opinion would be seen not in isolation (or worse, as a competitor with other strategies), but as responding to an element of the Basinwide Recovery Strategy, a principle or strategy in the Council's Fish and Wildlife Program, and a general mandate in the Governors' Plan. Although it might be seen as a bookkeeping exercise, such cross-referencing (including referencing the Tribal plan and Interior Columbia Basin Ecosystem Management Plan) could be the first step toward a mutually accepted, integrated, regional recovery plan.

\section{$\underline{\text { Tributary Habitat }}$}

Tributary habitat recommendations in the documents, in general, are inadequately linked with recovery strategies in the other Hs. The Fish and Wildlife Program does, however, stress the need for supplementation to be linked to watershed condition and to be integrated into subbasin planning. The consequences of putting more water back into tributaries were not clearly linked to mainstem habitat management or water quality issues such as temperature and dissolved gas. The role of salmon carcasses as vectors of marine-derived nutrients in salmon-producing watersheds was not adequately linked to harvest and escapement levels in most of the 
documents. Changes in habitat restoration tactics were not related to climate shifts or disturbance agents such as droughts, floods, or wildfires.

\section{$\underline{\text { Hatcheries }}$}

Linkages are not adequately identified. Linkage between hatchery production and harvest level is recognized, but the problems of developing selective and terminal fisheries are not adequately considered. Comprehensive harvest management plans must also be developed to cope with hatchery production if marine survival rates improve. Linkage between habitats and supplementation is acknowledged, but how subbasin planning and habitat modeling will inform decisions on where and how much supplementation is warranted is not clear. The cumulative detrimental effects of hydroelectric operations and other habitat conditions (e.g., water withdrawals) on mainstem habitats and how these effects limit the effectiveness of mitigation efforts using artificial production deserves more attention. A climatic regime shift producing abundant returns of salmon similar to those in 2000 and 2001 will undoubtedly create pressure for high harvest levels; how that pressure would be addressed was not articulated.

\section{$\underline{\text { Harvest }}$}

Harvest is only one source of mortality in the life cycle of a listed population. The life cycle analyses and CRI analyses are appropriate means to integrate all sources of mortality during the life of these fish. More in-depth consideration of two issues could have strengthened the discussions of harvest. First, the extent of fishery impacts sustainable by a stock is determined by its productivity in the existing environment and the status of the spawning population size. To assess the appropriateness of harvest impacts for recovery requires establishing spawning escapement goals for each production unit (group of spawning populations), predicting adult returns expected in the next generation, and a management plan for harvesting surplus returns or harvest restraints to increase the spawning population sizes. The Fish and Wildlife Program calls for the development of these production plans (subbasin plans) but the empirical basis for these assessments in the basin is believed to be quite limited. Second, the ISAB is concerned about the identification of mass-mark selective fisheries as a harvest tool without considering potential ecological interactions between hatchery and naturally produced fish. Mass-marking of hatchery fish and the development of selective fisheries to utilize this production provide an incentive for maintaining large-scale production of hatchery fish. What is not considered in this plan, however, is the potential for ecosystem effects associated with the continued release of large numbers of hatchery-produced fish.

\section{$\underline{\text { Models, Monitoring, and Evaluation }}$}

The four documents correctly identify the need for monitoring and evaluation of certain linkages, e.g., effect of naturally spawning hatchery fish on wild populations, effect of habitat improvement actions on returning numbers of spawners, and effects of supplementation on recovery of wild stocks. Generally, the documents continue to call for independent monitoring in the hope that effects of the linkages among the Hs can be evaluated. Examples of specific monitoring needs that have not received adequate planning include monitoring the effect of selective fisheries on wild stocks, monitoring natural survival rates of adult chinook in the ocean, 
and development of a permanent plan for monitoring of downstream survival of juveniles. In fairness to the documents, it is unrealistic to expect them to propose thoroughly monitoring and evaluating all linkages between the Hs. Given that limitation, the importance of identifying monitoring plans that respond to priority needs is all the more apparent.

\section{Climate, Hydrology, and Water Resources}

Linkages between climate, hydrology, and water resources and the various Hs are not adequately identified. Whereas there is some mention in the documents (especially the Basinwide Recovery Strategy) of the role of climate variability and change on ocean survival, it is basically ignored in the details of planning management actions except for changes in smolt transportation options during low flow years.

\section{$\underline{\text { Institutional Arrangements }}$}

The four documents do not identify improvements in institutional coordination within the Columbia River Basin that would make actions surrounding each of the Hs more effective. A common view in the Columbia River Basin is that scientific research will identify and resolve key uncertainties, and that once the necessary knowledge is obtained, effective decisions will become apparent. There are at least two difficulties with this belief. First, although new knowledge is always desirable and provides insight into unanswered questions, it invariably gives rise to new issues and consequently new uncertainties. Second, even if all the necessary data existed, it is unclear from the four documents that the institutional framework is adequate to utilize that information in appropriate ways to make and successfully implement decisions on salmon recovery. The region's institutions may simply be developing recovery plans that are consistent with the current organizational framework. Insufficient attention has been devoted to improving the way institutions incorporate scientific information into recovery strategies, and to ways in which coordination of efforts undertaken by different organizations to improve each of the Hs can be made more effective. 


\section{Introduction}

This report reviews approaches to salmon recovery put forward in four recent documents: the Four Northwest States Governors' Plan (Recommendations of the Governors of Idaho, Montana, Oregon and Washington for the Protection and Restoration of Fish in the Columbia River Basin, July 2000, here termed the Governors' Plan), the Northwest Power Planning Council's Plan (2000 Columbia River Basin Fish and Wildlife Program, November 30, 2000, here termed the Fish and Wildlife Program), the National Marine Fisheries Service's Biological Opinion (Final 2000 Federal Columbia River Power System Biological Opinion, December 21, 2000, here termed the BiOp), and the Federal Caucus Plan (Conservation of Columbia Basin Fish, December 21, 2000, here termed the Basinwide Recovery Strategy or All-H Paper). These documents in the aggregate provide a federal and state agency roadmap to salmon recovery in the Columbia River Basin for the years 2001-2010. In principle, the reports are in agreement about what measures should be taken in both the short- and long-term, and they are likely to provide the basis for allocating funds for salmon restoration projects.

There are other planning documents in the Columbia River Basin that are significant and important, but which are not reviewed here. These include tribal salmon recovery reports (e.g., Spirit of the Salmon Wy-Kan-Ush-Mi-Wa-Kish-Wit, June 15, 1995 draft), the US Forest Service and Bureau of Land Management's Interior Columbia Basin Ecosystem Management Plan, referenced by the acronym ICBEMP (Interior Columbia Basin Final Environmental Impact Statement and Proposed Decision, December 2000), the USFWS Biological Opinion on FCRPS operations affecting bull trout and Kootenai River white sturgeon (December 21, 2000), as well as various state salmon strategy reports. Some of these documents are quite large and contain details about specific programs, implementation strategies, and monitoring.

The purpose of this review is to address just the four recent planning documents and answer the general question "Do these documents collectively outline salmon recovery strategies that are likely to have a high probability of success?" The ISAB considered the conceptual foundation of different elements of the recovery documents, including the familiar " $H$ " categories: Habitat, Harvest, Hatcheries, and Hydroelectric operations (here included in a section on mainstem habitat and passage), as well as an examination of modeling and monitoring programs, climate and ocean conditions, and institutional arrangements. We did not review individual projects but rather evaluated whether the overall approaches expressed in the documents represented sound strategies in light of current scientific information. Each of the following sections contains a general summary and discussion of the salmon recovery documents. The conclusions of each section are presented as answers to a series of questions designed to evaluate the scientific adequacy, consistency, and integration of actions recommended in the reports.

The reports can be viewed at the following web sites:

Governors' Plan

http://www.governor.wa.gov/esa/srn/recommend.pdf

Biological Opinion

http://www.nwr.noaa.gov/1hydrop/hydroweb/docs/Final/2000Biop.html
Fish and Wildlife Program http://www.nwcouncil.org/library/2000/2000-19/index.htm http://www.nwcouncil.org/library/2001/2001-8.htm

Basinwide Recovery Strategy

http://www.salmonrecovery.gov/strategy.shtml 


\section{Mainstem Habitat and Passage}

Hydropower facilities and operations, primarily in the mainstem Columbia and Snake rivers, constitute one of the Hs in the shorthand commonly used to categorize the several aspects of environmental changes affecting salmon recovery in the Columbia River basin. Hydropower facilities have traditionally been viewed as encompassing (1) the mainstem dams and reservoirs from Grand Coulee Dam to Bonneville Dam on the Columbia River and from the Hells Canyon Dam to the confluence with the Columbia River for the Snake River, and (2) the system of storage reservoirs used to reshape the annual runoff to better match annual power generation needs and provide flood control. Part of the system is federal (Federal Columbia River Power System; FCRPS) while the remaining is owned and operated by public utility districts. Anadromous fish are blocked in the Columbia at Chief Joseph Dam, the dam immediately downstream of Grand Coulee. Operations primarily consist of management of water flows and reservoir elevations to use the water supplied by natural runoff and retained in upstream storage reservoirs for hydropower production (mainstem reservoirs have little flood storage capacity). Releases from storage reservoirs also generate hydropower, which is integrated with the mainstem hydropower operations. These facilities and their operation have been viewed as affecting anadromous fishes, particularly salmon, by interrupting upstream and downstream passage (complete blockage at storage reservoirs), creation of reservoirs that alter migration rates (and timing), and effects on water quality, principally temperature and dissolved atmospheric gases. A broader view has emerged in the last half-decade or so.

Although not identified by an $\mathrm{H}$, there is another mainstem use that affects planning for salmon navigation. Navigation by barge between ocean ports and the "Inland Empire" extending upstream to Lewiston, Idaho requires stable water elevations in reservoirs and locks in dams. Use of the mainstem for navigation constrains management options for salmon in the mainstem in ways that are often greater than for its use for hydropower.

Historically, a number of strategies have become engrained in regional planning for fish protection consistent with operating the mainstem hydropower and navigation system (and can be considered the status quo for gauging any changes reflected in the new set of plans). These strategies include fish ladders for upstream passage at mainstem dams, submerged screens in turbine intakes and their associated bypass facilities for downstream fish passage, regulation of reservoir elevations annually within a narrow elevation range (2-3 feet) partly to accommodate fish ladder elevations, flow augmentation from storage reservoirs to compensate in a small way during fish migrations for the major alterations created in the annual flow pattern (hydrograph), spill of some water over spillways during the downstream migration season to provide a migration route other than into turbine intakes, and collection of juvenile salmon at upstream dams for hauling by barge or truck (transportation) to points below the most downstream dam in order to fully bypass the stairstep of dams and reservoirs of the mainstem hydropower system. In addition to these implemented actions, several other actions have been included in previous plans but not implemented, including mainstem reservoir draw-down to speed migrations, and enforcement of annual rule curves for storage reservoir elevations that provide a compromise between water manipulations for downstream hydropower and the fisheries resources and recreation in the reservoirs. Each of these strategies had a technical/scientific basis that seemed 
logical at the time it was initiated and enough supporting logic to continue, if implemented. Transportation was once seen as an emergency measure to counter especially poor migration conditions during low-runoff years, but barging and trucking smolts has become a mainstay of passage management in spite of a number of unanswered questions about its effectiveness.

The mainstem issues are now broader than they were a decade ago. In the face of actual or imminent extinction of wild salmon stocks using the mainstem, and the necessity to produce ever more hatchery fish to yield acceptable harvest and adult returns, it was clear that a new paradigm or conceptual foundation was needed. Whereas the old paradigm considered the mainstem as a migration channel that needed structural or operational fixes, the new paradigm heralded by the Independent Scientific Group's 1996 "Return to the River" considered the mainstem as habitat. The mainstem was recognized as an essential complex of habitat types needed for the life cycles of a diverse array of anadromous fish species and stocks. But the ecological functions of the mainstem had been so simplified and degraded by the dam-reservoir system that it needed to be restored, either by removal of dams or by structural and operational modifications that more closely simulated the typical functions. Major changes in thinking were needed, not incremental adjustments to old approaches that were demonstrably unsatisfactory or insufficient for recovery.

The most controversial manifestation of the new perspective that considered the mainstem as an essential ecological support system for salmonids and other valued fish was the well-recognized drive to breach the four lower Snake River dams. Return to the River became not just a functional plea but a literal one as well -- to restore the free-flowing lower Snake River in its entirety from Hells Canyon Dam to the Columbia. Despite the decision to withhold that option until other alternatives are more fully explored (2000 Biological Opinion), that most drastic of fixes hangs over the region as strong motivation to seek and implement less socially disruptive but ecologically effective approaches.

This section evaluates whether a major change in perspective for the mainstem has been demonstrated by recommended actions in the current family of four management documents, the NMFS's 2000 Biological Opinion on Operation of the Federal Columbia River Power System, the federal government's Basinwide Recovery Strategy (including NMFS's Volume 2, Technical Information), the Council's Fish and Wildlife Program documents available to date, and the Governors' Plan. The critique of the strategies for the mainstem is divided into three parts, habitat, passage, and a summary that addresses the aggregate impression concerning the specific questions asked.

\section{Habitat}

\section{Biological Opinion}

The 2000 Biological Opinion recognizes the significance of mainstem habitat for survival of salmon. Considerable attention is given to water management plans to ensure adequate flow for downstream-migrating salmon (Action 3) and providing a more natural spring hydrograph (Action 14). Included are water quality plans, primarily for temperature and dissolved gas (Action 5). Downstream migrants are to be monitored for the concurrence of high temperatures and disease (Action 141). Specific items are included to provide habitat for spawning of chum 
salmon below Bonneville Dam, including flows (Action 15) and habitat modifications (Actions 156 and 157). At a broader level, the BiOp calls for the Corps of Engineers to do a feasibility analysis of modifying its current system of flood control operations to benefit the Columbia River ecosystem, including salmon (Action 35). An objective of this analysis would be to reconnect the river with its floodplain and reverse riparian simplification. Agencies are to develop a pilot study to assess the feasibility of enhancing the function of ecological communities of the mainstem corridor, mainly to reduce predation losses and enhance survival (Action 105). BPA and other agencies are to survey mainstem habitats, develop plans for improvement, and initiate improvements in three reaches (Action 155). Extending into the estuary portion of the mainstem, the BiOp asks for inventory of estuarine habitat and restoration (Actions 158-163). The BiOp calls for monitoring of associations between salmon presence and habitat attributes (Action 180). Delayed mortality through the hydrosystem (extra mortality) is to be reviewed and studied by NMFS (Action 195). All transportation actions are to include an evaluation of delayed mortality of transported versus in-river juvenile migrants (Action 47). Delayed mortality is considered further below from the perspective of the effects of dam passage.

\section{Basinwide Recovery Strategy}

The Basinwide Salmon Recovery Strategy, including its Volume 2, Technical Information (prepared by NMFS), explicitly recognizes the hypothesis in the Independent Scientific Group's Return to the River (ISG 1996, 2000) that important gains in salmon productivity could come from increases in mainstem spawning and rearing habitat. The Strategy includes steps to test this hypothesis by improving mainstem habitats of the Snake and Columbia rivers and the Columbia River estuary. The report cites a study by Battelle Pacific Northwest National Laboratory and the U.S. Geological Survey (PNNL and USGS 2000) that identifies habitat modifications that have occurred and suggests actions with the most potential to restore mainstem riverine habitat. The Strategy outlines an action plan that would (1) develop a baseline data set; (2) develop and implement a habitat improvement plan that, insofar as possible, mimics the range and diversity of historical habitat conditions; and (3) develop and implement rigorous monitoring and evaluation that would guide the mainstem habitat program. Many examples of useful habitat improvements are given, such as excavating and reconnecting backwater sloughs, silted-in lateral channels, and alcoves; reestablishing and enhancing historical wetlands; acquiring and enhancing riparian zones; and stabilizing daily water levels below dams. The report specifically recommends actions to improve the spawning habitat for chum salmon in the lower Columbia River.

The Columbia River estuary from the ocean to Bonneville Dam at river km 235 (mile 146) is singled out by the Strategy for more attention. Because relatively little is known about the estuary in relation to salmon life-cycle needs, a basic strategy includes (1) assessment, (2) adaptation of the current water-quality-oriented Lower Columbia River Estuary Program (LCREP) to the needs of salmon, (3) habitat acquisition and restoration, (4) floodplain restoration, (5) predator control, (6) education, and (7) a scientific monitoring and research program, focusing on a conceptual model describing critical linkages between estuarine conditions and salmon population structure and resilience. 


\section{Fish and Wildlife Program}

The 2000 Fish and Wildlife Program of the Northwest Power Planning Council expressly emphasizes a habitat focus. The Program "directs significant attention to rebuilding healthy, naturally reproducing fish and wildlife populations by protecting and restoring habitats and the biological systems within them." Furthermore, the Program document states that protection and restoration of mainstem habitat conditions must be a critical piece of this habitat-based program." The Program outlines a primary strategy of providing conditions within the hydrosystem "that most closely approximate the natural physical and biological conditions." An element of this strategy is to "manage the hydrosystem so that patterns of flow more closely approximate the natural hydrographic patterns..." a feature that is essential to maintaining mainstem habitat features. It is an explicit strategy to "protect, and where possible, expand, mainstem spawning and rearing areas." The current Program document does not go into detail about management of mainstem habitat. Rather, it stipulates that a "mainstem coordination plan" will be developed as a subsequent phase of the revision of the Program. This plan, to be completed by October 2001, is to contain measures for operation of the hydrosystem that mesh with the needs of the ESA-listed stocks.

\section{Governors' Plan}

Habitat reforms were key elements of recommendations for protection and restoration of fish in the Columbia River Basin by the Governors' Plan. Although provided in general terms, the governors recognized the importance of available water, accessible habitat over and beyond current mainstem habitat (with considerations for reestablishing mainstem habitat upstream of the Hells Canyon complex), protection and enhancement of habitats in the estuary, and considerations of predation as a source of mortality during mainstem and estuary passage. There was emphasis on tributary habitats, with particular attention to watershed planning efforts in the interior Columbia Basin.

\section{Passage}

Problems of fish passage at dams, both upstream and downstream, have received most of the attention and funding related to mainstem effects on anadromous fishes. This is not a subject, like mainstem habitat, that has lacked attention. This historical emphasis was justifiable, for lack of passage unequivocally ends a population's existence. Such has been the fate of populations upstream of Chief Joseph (Columbia River) and Hells Canyon (Snake River) dams. The main emphasis was on upstream passage. The bioengineering of fish ladders since the 1930s has, on the whole, been a classic success story even though some problems remain (Clay 1994). More recently, downstream passage has come to the forefront as heavy losses of smolts were quantified, especially in passage through turbines (Whitney et al. 1997).

\section{Current Actions}

Four notable areas of passage research have received attention recently. These are (1) reduction in turbine-induced mortality through development of more "fish-friendly" turbines, (2) development and testing of surface bypasses and collectors for creating passage routes for smolts 
that more closely mimic natural migration and cause less delay, (3) improvement of upstream passage for lamprey, since these species do not pass conventional salmon ladders well, and (4) re-evaluation of adult upstream migrations for fallback of adult salmon at dams.

\section{Turbine-Induced Mortality}

Mortality of 3 to $35 \%$ of fish passing through conventional Kaplan-type turbines in Columbia River basin dams has been well documented (Whitney et al. 1997). When migrating fish from the upper Snake River must pass eight dams, cumulative loss is high. Considerable effort has been spent on submersible screens to divert fish into bypasses at turbine intakes, but the protection provided still leaves many fish being killed or highly stressed in turbine passage (Mighetto and Ebel 1995). Recent attention has thus been directed at improving survival of fish passing through turbines by reassessing the engineering design of turbine blades and housings.

Fish-friendly turbines are being developed by the Army Corps of Engineers and the Department of Energy. The Corps has concentrated on minimizing the gaps between turbine blades and the housing, under the assumption that fish are being killed or injured by being forced through these gaps (NAI et al. 2000). Turbine runners (the blade assemblies) are slated for repair or replacement at most Columbia River dams over a several-year period, and upgrades for improved fish passage can be included. Such "minimum-gap runners" have been tested recently at Bonneville Dam. The Department of Energy is investigating two options, a minimally modified conventional turbine assembly and a new "Archimedes screw" design (Odeh 1999). The former could be implemented at current powerhouses; the latter would require a new powerhouse configuration. Both are at an early stage of prototype design and testing.

\section{Surface Bypasses}

Observations that juvenile salmonids can be passed over dams readily in surface flows have stimulated development of surface bypasses (Whitney et al 1997; Johnson et al. 1997). Salmon migrants generally pass in spill when it is occurring. Surface sluices for ice and trash have passed a disproportionately high number of smolts compared to the amount of water spilled. Wells Dam, which has spillways on top of the turbines, passed large numbers of smolts in a small amount of spilled water. This was presumed to be because fish followed turbine-intake flows toward the spillways but then remained in the surface water to be spilled rather than diving into the turbine intakes.

Despite a great deal of expense for design, construction and testing of prototype surface bypasses, performance has not met expectations. The main deficiency is the inability of the bypasses to attract fish to their entrances in the face of competing flows to turbine intakes or spillways. Studies are currently underway to improve recognition of the bypass entrances through induction of river-like turbulence as a guiding mechanism (Coutant 1998; Darland et al. 2000). 


\section{Lamprey Passage}

Lamprey do not successfully use fish ladders designed for upstream passage of salmon. Although some are successful, the numbers are low enough that the lamprey populations are in steep decline. Lamprey adults are considered to be of cultural significance to native peoples and their juvenile stages have food-chain significance for Northwest river ecosystems. A small amount of research is being undertaken to improve ladders for lamprey passage (USACE 2000).

\section{Adult Passage}

There has been renewed interest in adult salmon passage, particularly reevaluation of the accuracy of fish counts at dams, questions about inter-dam survival, and fallback of adults over spillways at dams. These problems have been addressed by research in the Corps of Engineers' Anadromous Fish Evaluation Program (USACE 2000).

\section{Biological Opinion}

The BiOp addresses specific juvenile and adult survival levels during passage, both direct and indirect. The $\mathrm{BiOp}$ is "aimed at improving passage survival through the FCRPS dams and reservoirs" with actions related to spill, flow management, and improved passage facilities. Delayed mortality (extra mortality) as well as immediate mortality is to be evaluated both for inriver migrants and those transported (Action 47). Water management plans for flows emphasize assisting downstream migration (Actions 3, 14). Surface bypasses are to be included in projects, and the hydraulics of forebays studied to enhance attraction (Actions 85, 86). Fish-friendly turbines are encouraged (Actions 88, 89). Juvenile survival in the hydrosystem is to be monitored (Actions 185-190) and also in the estuary below Bonneville (Action 195). These examples are not comprehensive, but they give a flavor of the BiOp's focus on passage issues. The BiOp is consistent with the Basinwide Recovery Strategy.

\section{Basinwide Recovery Strategy}

The Basinwide Recovery Strategy includes actions to improve passage. Specific passage upgrades for juvenile fish and individual dams are recommended, including relocation of bypass outfalls, refined screens and bypass facilities, development of surface bypasses, spillway modifications and more effective spill, improved turbine operations and design, predator management, as well as habitat management in the mainstem and estuary. There are to be improvements in flows to aid migrating juvenile and adult fish. Flood control operations are to be adjusted to reduce risks to fish. Fish transportation is to spread the risk (mix transport and inriver migration), reduce trucking, and continue to study the delayed mortality issue. The report notes the need to have similar actions on the non-federal dams, although as part of the appropriate ESA consultations, FERC processes, and Snake River adjudication. The Basinwide Recovery Strategy is consistent with the BiOp. 


\section{Fish and Wildlife Program}

The Program recommends a much more biologically based passage program than in the past, with "actions to improve dam-passage survival that are biologically sound and economically feasible" and that benefit the "range of species in the river" (biological diversity) and that "fit natural fish behavior patterns." Survival in the natural river is to be the baseline against which to measure the effectiveness of other passage methods. Fish passage efforts, as well as other hydrosystem operations, "should be directed at reestablishing natural river processes" with the strategy to "most closely approximate the natural physical and biological conditions." Continued testing and development of surface bypass systems is called out, as is the relocation of bypass outfalls when problems with predation, injury, and mortality occur. Modification of turbines to enhance fish survival is encouraged. The habitat principles outlined above are applied to passage through reservoirs. While seeking to improve inriver conditions, the Council's Program recognizes the value of smolt transportation as a transitional strategy, and endorses both a "spread-the-risk" approach of using both inriver passage and transportation, while giving priority to "funding of research that more accurately measures the effect of improved inriver migration compared to transportation." As for habitat issues, the 2000 Program anticipates a more specific "mainstem coordination plan" by October 2001.

\section{Governors' Plan}

The more general Governors' Plan acknowledges that the hydrosystem has been improved for fish passage but that the system still adversely affects fish survival. The plan supports further modifications to benefit fish, with expedited schedules. Preference is given to strategies that provide best survival in the river over transportation, which is seen as a transitional strategy. The importance of spill is recognized, as is the need to improve its use in terms of duration, timing, and quantity. Flow management is seen as a part of mainstem strategy. Although flow augmentation is controversial, there are positive attributes that need to be determined and used. Side effects, such as water quality issues need to be resolved. Cooperative agreements, such as those in place for the Hanford Reach, should be explored more widely.

\section{Summary}

Do the documents in aggregate represent an adequate response to the problem? Do the documents describe a course of action that is likely to achieve regional goals such as ESA delisting, harvestable fish, and sustainable ecosystems?

Current salmon restoration documents recognize the issues of mainstem habitat (i.e., ecosystem structure and function) far more than did any earlier strategies. Specific approaches recommended in the ISG's Return to the River are included as testable hypotheses for improvement of overall salmon survival. In addition, the more traditional approaches for monitoring and improving fish survival during hydrosystem passage are retained and expanded upon. These include spill, bypasses, intake screens, and transportation. In aggregate, the ecosystem and dam-fix approaches hold promise for increasing survival to levels consistent with population growth rather than continued decline. 
The documents in aggregate are a significant response to the mainstem habitat and passage problem, and represent a major evolution in thinking. The Governors' Plan is essentially a statement of social (political) support for restoration activities. This step is essential for success. Next in level of detail is the Council's Fish and Wildlife Program, which at this stage in its development is a statement of principles, goals, and general strategies. More detailed courses of action are expected to follow as the Program is further developed. The Basinwide Recovery Strategy further outlines strategies, which are restated in a different format in the Biological Opinion (that also includes specific action items). The course of action has a strong life cycle and ecological orientation, which represents a more realistic strategy than had been expressed previously.

The general optimism over the new plans for the mainstem depends, of course, on the level of implementation. The old plans had some action items and measures that were ecologically oriented, too, but these were often ignored in practice. New action items for ecological restoration are still largely feasibility studies that should be completed and assessed. In contrast, the traditional actions (e.g., flow specification, screens, transportation) have a momentum of past history that makes it more likely that they will be continued and even expanded upon incrementally, perhaps to the detriment of the newer ecologically oriented initiatives. For example, the artificial transportation program for smolt migration is still advocated in the Biological Opinion, despite a significant trend toward adopting an overall recovery strategy that moves more toward natural ecological processes (either directly or through engineering designs that mimic nature), a direction the ISG termed moving toward more normative conditions. The ISAB has previously reviewed the transportation program, pointing out many problems with it as a recovery strategy for the long term. Only the operational recommendations to phase out truck transportation in favor of barging and extending the season to avoid selecting only peak migrants seem to have been heeded in the current plans.

\section{Do the documents in aggregate represent a change in the status quo or a continuation of past efforts?}

The documents represent a significant change in the status quo. The current principles, justifications, and the specific recovery actions are strongly ecological and life cycle based, in contrast to technologically justified engineering fixes stressed earlier (e.g., specified flows and dam modifications). Many past efforts are also continued, but with a decidedly more ecological and life-cycle basis, for example, emphasis on ecologically more compatible surface bypasses and weirs for fish passage at dams rather than artificial screening systems. Previous recovery documents said little about mainstem habitat, whereas the mainstem is now recognized as having important habitat functions that can be managed uniquely.

However, there are still vestiges of obsolete salmon biology in the Biological Opinion. For example, in section 6.2.9 there are many notations that mainstem habitat features such as riparian vegetation, food, and space are not needed by specific stocks in the mainstem. Such inaccurate statements foster further simplification of the mainstem ecosystem based on a narrow view of a few prominent stocks, when a return to habitat complexity is needed for the entire assemblage of diverse stocks and species. 
Do the documents provide a consistent course of action?

Recognizing that each document has its own specific objectives, audience, and level of detail, the documents seem quite consistent about protecting and restoring habitat values in the mainstem and providing fish passage opportunities that better match natural migration needs.

The declaration of a flow emergency in 2001 that vacated the terms of the Biological Opinion and other recovery plans raises further issues. What criteria are used to determine when fish recovery actions must give way to the needs for hydropower? Some unwritten criteria were clearly exceeded in 2001. It would be useful to know what these criteria were, or alternatively, to see the plans establish a process for creating criteria explicitly for use in the future. The plans in aggregate are silent on such emergency criteria from the fish recovery perspective.

Are linkages among strategies for dealing with the 4 H's adequately identified?

The documents could have done more to point out their mutual consistency, and perhaps point out a few items where they were inconsistent. Cross-linking of items in subsequent drafts could be useful for coordination within the basin. Thus, implementation of a certain mainstem-related Action from the Biological Opinion would be seen not in isolation (or worse, as a competitor with other strategies), but as responding to an element of the Basinwide Recovery Strategy, a principle or strategy in the Council's Fish and Wildlife Program, and a general mandate in the Governors' Plan. Although it might be seen as a bookkeeping exercise, such cross-referencing (including referencing the Tribal plan and Interior Columbia Basin Ecosystem Management Plan) could be the first step toward a mutually accepted, integrated, regional recovery plan.

Finally, the dam breaching option is not dead, at least in the minds of a significant population of Columbia River Basin residents. These recovery plans will be held up continually to strong scrutiny with the breaching option as the standard for comparing ecological recovery in the mainstem. Whether or not that standard is realistic technically (i.e., will a drained reservoir readily return to a normally functioning river), it is certainly impressed into public perceptions. 


\section{Tributary Habitat}

The Fish and Wildlife Plan, and to a lesser extent the Governors' Plan, tend to defer to the processes outlined in detail in the BiOp and Basinwide Recovery Strategy for protection and restoration of tributary habitat. It is in these two reports that most of the details regarding tributary habitat improvements are found.

\section{Biological Opinion}

All four documents divide Columbia River Basin freshwater salmon habitat into three zones: (1) tributary habitat, including all subbasins of the Columbia and their respective river networks (e.g., John Day River subbasin), (2) mainstem habitat, including the mainstem Columbia and Snake Rivers, and (3) estuary habitat, including the lower $235 \mathrm{~km}$ (146 mi) of the Columbia River above the river mouth. In terms of the number of identified action items in the $\mathrm{BiOp}$, habitat actions account for $7.5 \%$ of the total (Figure 1). Approximately two-thirds of the action items are devoted to hydroelectric operations. This does not mean that funding for habitat improvements will amount to less than $10 \%$ of the Columbia River Basin salmon recovery budget, but rather that the BiOp was much more specific in terms of hydroelectric operation modifications than it was for other Hs.

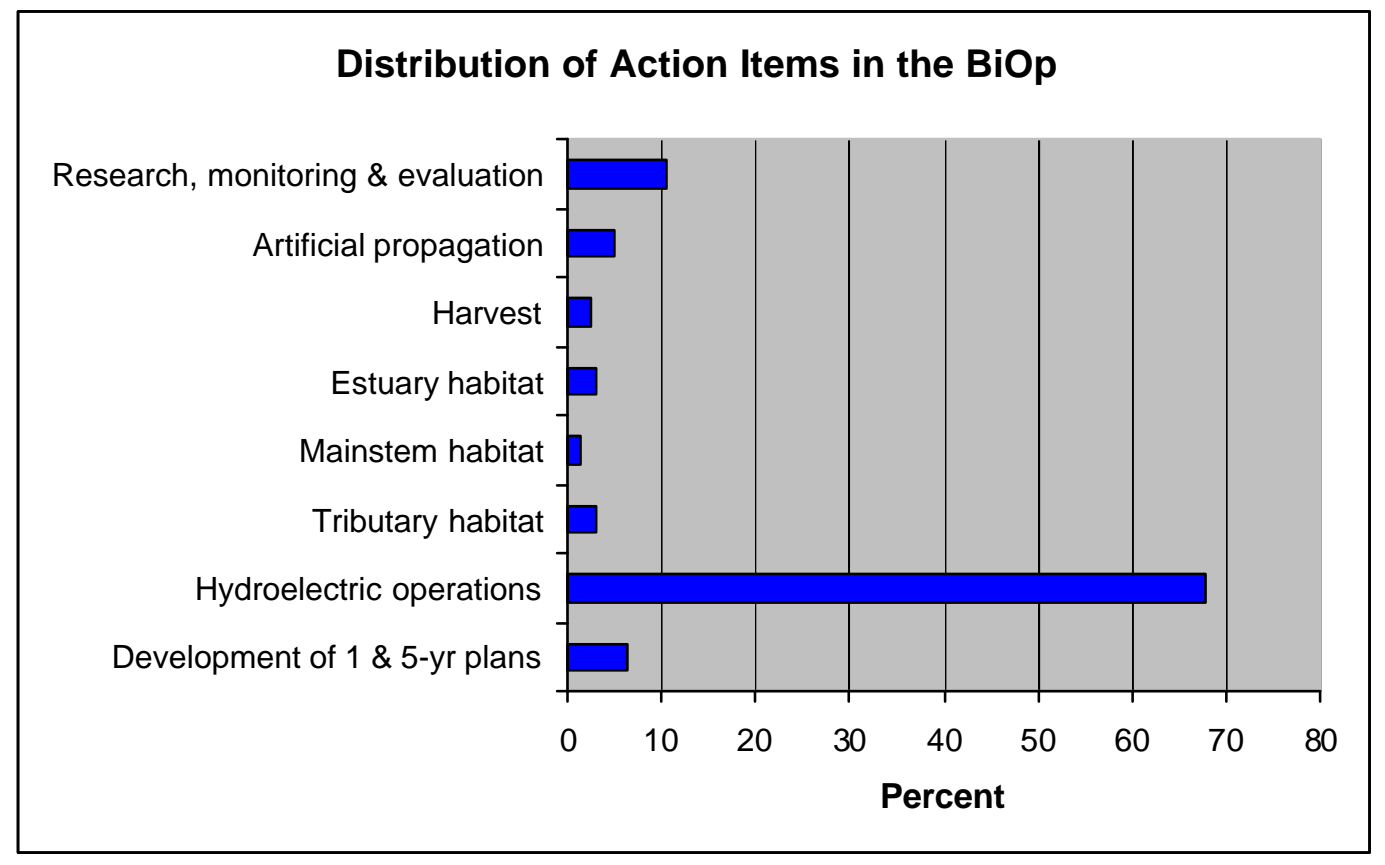

Figure 1. The distribution of action items specified by the December 21, 2000, BiOp among various salmon restoration categories. 
Six tributary habitat action items are identified in the BiOp, representing $3 \%$ of the total. The objectives of these actions are given as follows.

- Water quantity - increase tributary water flow to improve fish spawning, rearing, and migration.

- Water quality - comply with water quality standards, first in spawning and rearing areas, then in migratory corridors.

- Passage and diversion improvements - address in-stream obstructions and diversions that interfere with or harm listed species.

- Watershed health - manage both riparian and upland habitat, consistent with the needs of the species.

In abbreviated form, the six tributary habitat action items are:

Action 149: Bureau of Reclamation shall initiate programs in three priority subbasins per year over five years... to address all flow, passage, and screening problems.

Action 150: BPA shall fund protection of currently productive non-Federal habitat.

Action 151: BPA shall... experiment with innovative ways to increase tributary flows by, for example, establishing a water brokerage.

Action 152: The Action Agencies shall coordinate their efforts and support offsite habitat enhancement measures undertaken by other Federal agencies, states, Tribes, and local governments.

Action 153: BPA shall... negotiate and fund long-term protection for 100 miles of riparian buffers per year.

Action 154: BPA shall work with the NWPPC to ensure development and updating of subbasin assessments and plans.

These action items appear to be consistent with the stated objectives of the BiOp, Basinwide Recovery Strategy, and Fish and Wildlife Plan. Water quality and quantity are highlighted as priority resources for salmon recovery (Actions 149 and 151) and emphasis is placed on subbasin planning (Action 154) and riparian protection (Actions 150 and 153). Both the BiOp and the Basinwide Recovery Strategy accept the aquatic conservation strategies detailed in the ICBEMP preferred alternative for the Interior Columbia Basin, and in the Record of Decision for the Northwest Forest Plan for the Columbia River Basin west of the Cascade Mountains, as being adequate for salmon recovery on federal lands. However, there may be targeted projects on certain federal lands where outside funding (e.g., BPA) occurs. Many action items for tributary habitat, however, pertain to state, Tribal, municipal, and private lands. Although not explicitly stated in any of the four documents, the assumption is that tributary habitat on non-federal lands tends to be of lower quality than in federally managed areas. 


\section{Basinwide Recovery Strategy}

The short-term approach of the BiOp, Basinwide Recovery Strategy, and Fish and Wildlife Program is to undertake, as funding permits, an aggressive program to remove passage barriers, screen water diversions, increase streamflow, restore water quality, and protect high quality habitats through land purchases and conservation easements on non-federal lands. There seems to be little to question or criticize scientifically in this approach, as the benefits of each of these actions to salmon are readily apparent. Responsibility for implementing many of the actions falls largely on the Bureau of Reclamation, which will need considerable funding to carry out the objectives. Whether the actions are enough to make a significant improvement basinwide will in part depend on agency staffing and budgets.

The process for achieving long-term objectives of the BiOp and Basinwide Recovery Strategy (Table 5, pages 50-52 of Volume 1 of the Basinwide Recovery Strategy) rests heavily on subbasin assessment and planning, coupled with yet to be determined sets of habitat performance standards involving water quantity and quality, temperature, fine sediment, and large wood. The justification of this process, as opposed to imposing a blanket set of habitat standards and restoration guidelines throughout the basin, is that subbasin assessment and habitat standards can be tailored to the biophysical setting of the subbasin in order to produce habitat goals that are ecologically realistic.

Progress in achieving habitat recovery objectives will be measured by trends in the improvement of key habitat parameters: instream flows, amount and timing of sediment inputs to streams, riparian conditions, and habitat access. Accordingly, the condition of subbasins will be based on assessments using, for the most part, two diagnostic tools -- one carried out by NWPPC and the other carried out by NMFS. These tools, respectively, are Environmental Diagnosis and Treatment (EDT) and the Salmon Watershed Analysis Model (SWAM). EDT is an expert system and empirically based decision support model that relates environmental attributes to salmon life history-specific survival at the scale of a $6^{\text {th }}$-field hydrologic unit code (HUC). EDT analysis of Columbia River subbasins is currently underway and is schedule for completion in 2001. SWAM is a coarse-scale model of the statistical association of salmon productivity with watershed characteristics at the scale of larger $4^{\text {th }}$ - and $5^{\text {th }}$-field HUCs. SWAM analyses for several major Columbia River subbasins have been completed. Together, the outputs from EDT and SWAM are meant to inform subbasin planners about the current condition of the subbasin, and provide a basis for forecasting the relative improvement in salmon productivity that would result from different restoration options. According to the BiOp, these modeling tools will also be used to update CRI estimates of population change.

The ISAB is hopeful that the subbasin assessment process proposed in the Basinwide Recovery Strategy will succeed. It appears to be consistent with the goals of the Fish and Wildlife Program and, with limitations, the development of local recovery plans in the Governors' Plan. One very important contribution of the salmon recovery documents, in terms of tributary habitat, is that they will force the region to undertake a thorough inventory of existing conditions so we can establish where we are now, where we want to go, and how we will get there. 
Under the Basinwide Recovery Strategy, performance standards will be established for instream flows, amount and timing of sediment inputs to streams, riparian conditions (streambank integrity, large wood input, and channel complexity), and habitat access. The basis for establishing these performance standards is summarized in the following paragraph (Volume 2, page 14):

“... meaningful performance measures can be established to guide management. We will identify certain ecological problems that limit species productivity, steps that need to be taken to address these problems, and ecological and management indicators that allow us to judge whether the steps we are taking are successful. Because of the time needed to detect ecological and physical changes, management indicators showing that the right steps are being taken will be crucial for the first several years. Thus, both management and ecological indicators will be included in the habitat performance measures.

Ecological indicators must be related to the biological responses of the species of interest. Biological responses most sensitive to habitat changes are egg-to-smolt survival and the fitness of smolts. Linking these biological measures to performance standards that are good indicators of increases in salmon productivity (e.g., population growth rate) will provide the information needed to evaluate overall success. Performance standards can also be developed now that should be good indicators of increases in salmon productivity."

These two paragraphs express a sense of optimism that tributary habitat recovery can be addressed by what amounts to a three-step process: (1) identifying environmental factors limiting salmon production, (2) establishing a quantitative relationship between egg-to-smolt survival and changes in each of the limiting factors, and (3) determining the effect of management actions on changes in each of the limiting factors.

Consider each of these steps, beginning with limiting factor analysis. Although it is not explicitly stated in the Basinwide Recovery Strategy, freshwater limiting factors for salmon populations in any given subbasin will not be known with a high degree of certainty and are likely to change from year to year. The documents suggest they will be identified using EDT, SWAM, or some other expert system tool. Being able to determine the relationship between changes in these factors and changes in egg-to-smolt survival requires actual data or a model. Since, for the most part, data will not be available within the subbasin and for the species in question, models of the incremental response of survival to changes in environmental variables, usually based on laboratory experiments, are likely to be employed. Finally, because of delays between restoration implementation and the condition of the presumed limiting factor (e.g., the time it would take a riparian zone to begin producing large wood for stream habitat after riparian grazing damage was ended), it is likely that models will be used to forecast expected improvements in the performance measures within the timelines of the $\mathrm{BiOp}$ and Basinwide Recovery Strategy.

Thus for each step in the process, management decisions will probably be based on response models. While this may be unavoidable, habitat managers should be aware of some potential 
pitfalls. First and most important is the problem that any assessment of limiting factors will be constrained by the possibilities being considered. If only four factor categories are included in assessments (instream flow, sediment input, riparian condition, and habitat access), conclusions will point to one or more of these environmental factors as being limiting. Other potentially important factors, e.g., nutrients, are not even considered. This may or may not be a problem, but we will not know unless assessments are broadened.

Second, the current process outlined in the Basinwide Recovery Strategy is unclear about how interactions between habitat factors are treated. The effect of one factor on salmon survival may be strongly influenced by the state of other factors, and both EDT and SWAM will need to account for such interactions.

Third, most habitat models do not consider landscape-level disturbances, except perhaps as exogenous events that contribute to habitat degradation. While wildfires result in short-term increases in stream temperature and sedimentation, in the long term they serve the important ecological function of contributing new wood, coarse sediment, and nutrients to streams - all needed for salmon productivity. Provisions for restoring or emulating natural disturbances are not adequately addressed in any of the four documents, yet they were a major consideration in ICBEMP. None of the performance standards in the Basinwide Recovery Strategy is discussed in the context of natural disturbance and recovery. However, the Fish and Wildlife Program does acknowledge that watersheds are dynamic, and that recovery strategies should be matched to a habitat's potential for regaining ecological functions.

Finally, the emphasis on modeling to establish performance standards and evaluate their efficacy can lead to modeling wars, in which putative relationships between environmental parameters and salmon survival are used to shape policy recommendations that serve different interests. Although the Basinwide Recovery Strategy expresses optimism that consensus can be achieved through the subbasin assessment and planning process it remains to be seen whether scientists in the region can agree on consensus performance standards for tributary habitats, as attempts to do this in the past have generally not been successful.

\section{Streamflow}

In a very basic sense, the documents correctly identify one of the fundamental habitat problems in the Columbia River Basin - there is not enough water to provide for salmon and all other potentially beneficial human uses. Taking action to improve water quantity and quality may well be the single most important step in tributary habitat recovery. Surprisingly, there are relatively few analyses of the relation between salmon productivity and streamflow, and those that exist were largely conducted outside the Columbia River Basin. Yet nearly all have identified a positive association between the quantity of streamflow available for juvenile salmon rearing and the rate of subsequent adult return (e.g., Smoker 1955; Scarnecchia 1981; Botkin et al. 1995).

Of course, the number of salmon returning to the Columbia River is strongly influenced by ocean conditions and other factors. In fact, the biological details of the positive association between discharge and subsequent run size are very much open to debate. Nevertheless, the relationship of fresh water quantity to salmon productivity does provide circumstantial evidence that 
improving streamflow, especially during years when water is scarce, will aid salmon recovery. The phrase "just add water", while certainly oversimplifying the needs of tributary habitat, may contain enough truth to anchor many restoration projects.

Whether the strategies are able to mount water conservation programs effective enough to really make a difference is another question, particularly during drought years such as 2000-2001 when water is scarce. Water in many important salmon-producing rivers in the Columbia River Basin is already oversubscribed, and much has been written about western water law and the attitudes of local landowners toward water buy-back programs. There have been successes, but there have also been failures. If the voluntary water brokerage program (Action 151) is to work, it will require considerable funding, strong BPA and BOR leadership, and most importantly, local political support. This will not be easy, and it may take decades to fully implement.

A second important unknown is whether federal agencies will be able to agree upon a methodology for estimating instream flow needs. The Basinwide Recovery Strategy states that in 2001 "BPA will fund development of a methodology for ascertaining instream flows that meet ESA requirements" (Basinwide Recovery Strategy, Volume 2, page 7). The most widely used methodology is currently the Instream Flow Incremental Methodology (IFIM), but use of this method has also been widely criticized (e.g., Annear and Conder 1984; Mathur et al. 1985; Hatfield and Bruce 2000; Kondolf et al. 2000) if not thoroughly calibrated with local data. It is possible that EDT will be used to estimate needed instream flows, but this is not explicitly stated in any of the documents. The Basinwide Recovery Strategy also suggests that ESA and Clean Water Act Total Mean Daily Loading (TMDL) flow requirements be combined. This objective will require a high level of agency coordination.

\section{Barrier Removal}

All four documents also emphasize the removal of barriers to fish passage as an important shortterm tributary habitat remedy. In a sense removing an unnatural barrier is equivalent to adding water; in both cases new habitat becomes available. Although there have been many surveys of fish passage barriers in the Columbia River Basin, many more are needed, including assessments of barriers to upstream juvenile passage - one of the most overlooked aspects of fish blockage problems. State agencies and tribes usually take the lead in surveying non-federal lands, while the USFS and BLM do most of the surveys on federal lands.

Road crossings are an especially significant problem. A number of guidelines for adult salmon passage at road crossings exist. Recently, the USFS has developed a diagnostic tool for identifying passage problems at road crossings (see www.stream.fs.fed.us/fishxing) as part of its new road policy. Improved coordination and data sharing among federal and state agencies, and tribes, could speed the inventory process and facilitate identification of areas for priority attention. There are also other types of barriers that deserve attention including temporary pushup dams, permanent low-head dams for irrigation and livestock water, and dewatering that creates intermittently flowing channels.

Barrier removal constitutes a potentially powerful tactic for improving tributary habitat but if overall survival of a population is limited by degraded habitat in the lower reaches of the river, 
improving habitat in the upper reaches will not solve the problem. However, it is worth noting that high quality habitats may be located upstream from natural barriers such as waterfalls. There will be inevitable pressure to provide fish passage around natural barriers, but doing so places native biota above them at risk when salmon and steelhead act as competitors, predators, or disease vectors. The ISAB cautions against providing passage around natural barriers until site-specific ecological consequences of doing so are understood.

\section{Measures of Restoration Success}

The habitat parameters suggested in Volume 1, Table 3 (page 40) of the Basinwide Recovery Strategy (stream miles meeting water quality standards, stream miles with adequate instream flows, stream miles opened to fish access, number of diversion areas screened, acres or miles of riparian habitat protected/restored) do represent useful measures of recovery success, and we hope serious efforts are made to inventory them on an ongoing basis. These performance measures are to be used in EDT analyses to estimate potential benefits from habitat actions and to gauge success "using a scientifically focused and rigorous evaluation program" (page 41). The ISAB notes that such a program has not yet been developed, nor have details of who will fund and carry out monitoring studies been given. We further note that the suggested performance measures deal mostly with streamflow, water diversion screening, and access. Other potential limiting factors (sediment, temperature, large wood, and habitat complexity) are not mentioned. While there are significant methodological problems in obtaining accurate samples of these other factors, ignoring them in tributary habitat monitoring programs seems risky. Perhaps a reasonable solution would be to fund intensive monitoring programs in subbasins that have been identified as priority areas for immediate restoration (Basinwide Recovery Strategy, Table 2, Volume 2, page 17) and including a broad suite of habitat variables.

Action 179 of the BiOp calls for completion of NMFS' viable salmonid population (VSP) analysis by 2003. This analysis will include establishing recovery goals for each ESU, to be carried out by Technical Recovery Teams (TRTs). In Table 9.6-4 of the RPA chapter (page 9164), habitat capacity for each ESU is to be determined in 9-10 months, evaluation of multiple management options involving the four Hs is to be completed in 12-18 months, and based on subbasin assessments, to identify the principal factors responsible for population declines by 1.5 years. This is an extremely optimistic timetable. Validation of the SWAM model, which estimates watershed capacity, will need to be completed in a wide variety of biophysical settings. Habitat capacity will vary from year to year in response to climate and disturbance frequency, so there will be wide variation around capacity estimates. As a result, predicting the incremental improvement in salmon production -- egg-to-smolt survival and smolt condition -- resulting from habitat restoration will have a very high level of uncertainty. Table 4 in Volume 2 of the Basinwide Recovery Strategy (page 33) estimates incremental increases in smolt production for five ESUs if overall habitat conditions were improved from "fair" to "good". These estimates range from near zero to $80 \%$, with an average variability in the estimate being on the order of 30 $50 \%$. This contrasts markedly with incremental estimates of smolt survival improvements at dams (often given with two significant digits), where more data are available.

Finally, there are challenges in relating fish population response to management actions. On one hand, long-term records of abundance, e.g., spawner counts from index streams or experimental 
watershed studies in which populations have been monitored over time, have proven quite useful for detecting trends (Hall et al. 1987; Hartman and Scrivener 1990; Kareiva et al. 2000). On the other hand, analyses of salmonid population variability have demonstrated the difficulty of detecting the signature of management effects such as habitat degradation or restoration activities (Lichatowich and Cramer 1979; Hall and Knight 1981; Hall 1984; Hilborn and Winton 1993). In the Pacific Northwest, multi-year salmonid population studies have estimated an average interannual coefficient of variation for coho, steelhead, and sea-run cutthroat trout juveniles, smolts, and adults to be approximately 50-60\% (National Research Council 1996). In a separate and independent analysis of salmonid metadata from the Columbia River Basin, Ham and Pearsons (2000) estimated an interannual coefficient of variation for fall chinook, spring chinook, and steelhead adults of 70-80\%. If these two fairly similar estimates approximate the interannual variability of anadromous salmonid populations, it will take two or more decades to statistically detect all but the most dramatic of changes in population responses to habitat restoration. Similar problems occur in trying to decipher management-related change in resident fishes (Rieman and Myers 1996; Maxell 1999). And this assumes that population estimates are accurate; if they are in error as is likely the case (Dunham et al. 2001), the ability to detect change is further limited.

There is also a time lag between physical cause and biological response that further complicates tributary habitat restoration assessment. Changes in land management may take decades to produce significant changes in stream channels or fish populations. In some cases, delayed responses are precipitated by rare natural events in watersheds where management activities occurred years before (Harding et al. 1998; Ziemer 1998). By the time changes are detected (assuming that we can even detect them) there is likely little that can be done (Montgomery 1995).

This is not to say that fish populations should not be monitored. They should (Botkin et al. 2000). Repeated population censuses are essential for trend detection and for certain types of environmental correlation analysis. However, abundance estimates will probably not yield answers to habitat restoration questions over time periods that are less than several salmon generations. Evaluating population performance standards is likely to be stymied by the inherently high levels of variability and the difficulty of achieving accurate censuses.

For all these reasons the ISAB is concerned that tributary habitat monitoring programs will not be up to the task of providing timely answers within the 3,5,8, and 10-year checkpoints identified in the BiOp and Basinwide Recovery Strategy. Without this information it will be difficult to accurately model population change using the CRI technique.

\section{Fish and Wildlife Program}

The Fish and Wildlife program, while conceptual in nature, has a very strong habitat emphasis. Each of the eight scientific principles providing the foundation for the program relates to some aspect of ecological function provided by natural habitats. The ISAB agrees that these principles are consistent with current scientific knowledge. 
The ISAB also agrees that the strategy of applying different habitat protection or recovery tactics to different parts of the landscape depending on whether habitat condition is currently "intact", "restorable", "compromised", or "blocked" makes ecological sense. Such a hierarchical approach is similar to the approach recommended by the Natural Research Council in Upstream (NRC 1996). The table outlining possible restoration strategies under different levels of habitat degradation is one of the few instances in any of the documents where habitat actions are linked to appropriate artificial production strategies. While the decision on what type of artificial production, if any, is needed in a given watershed is ultimately a policy call, it was gratifying to see an explicit connection between habitat condition and hatchery options.

The strategy of building outward from core areas of healthy populations in intact habitats is consistent with metapopulation theory, and is similar to the approach recommended in ICBEMP (for the interior Columbia River Basin) and the Northwest Forest Plan (for that part of the Basin west of the Cascade Mountains). The development of subbasin plans is highlighted in the Fish and Wildlife Program, and the procedure is essentially that described above for the Basinwide Recovery Strategy. The ISAB hopes that subbasin plans will follow the strategy outlined in the Fish and Wildlife Program and work toward building an interconnected network of good quality habitats along the river systems. The subbasin planning and development process, however, has not yet taken place so we have no basis at this time of judging how well subbasin plans will adhere to this principle.

\section{Governors' Plan}

The Governors' Plan is very general with respect to tributary habitat recovery. The primary emphasis is placed on enhancing partnerships between federal, state, and private habitat managers. The Governors' Plan supports voluntary water conservation measures and "the development of water markets to effect changes among willing buyers and sellers". The plan also endorses the creation of salmon sanctuaries; however, no details are given other than a comment that efforts should be focused on locations that promise the greatest benefits for fish.

In emphasizing the importance of local recovery planning, the Governors' Plan seems to imply that tributary restoration strategies developed by local and tribal governments will be somehow more effective than federally imposed plans. No scientific reasons are given to support this assumption. The Governors' Plan also asserts that state, not federal, authorities designate priority watersheds for subbasin planning.

With respect to federally managed lands in the interior Columbia Basin, the Governors' Plan concludes that modifications to current management practices are needed. The statement that "the interior Columbia River Basin needs a balanced strategy that can provide for stable and predictable multiple-use management on federal lands for fish and wildlife and other uses while permitting needed flexibility, particularly on private lands" was very difficult to interpret but seems to affirm the states' position that protection of fish and wildlife habitat on federal forests and rangeland should be held to a higher standard than on state-regulated lands. 


\section{Summary}

Do the documents in aggregate represent an adequate response to the problem? Do the documents describe a course of action that is likely to achieve regional goals such as ESA delisting, harvestable fish, and sustainable ecosystems?

The Governors' Plan and the Fish and Wildlife Program outline conceptual or procedural approaches to tributary habitat restoration, but they do not explicitly consider limiting factors or habitat performance measures. Because they lack technical details, it is impossible to judge scientifically whether they represent an adequate response to the problem. The Fish and Wildlife Program, however, does rest on sound ecological principles and identifies geographic subunits within the Columbia River Basin - ecoprovinces and subbasins - that bound bioregional habitat recovery planning. Some ecoprovinces roughly correspond to ESU designations for listed salmon, and it is gratifying to see analysis and planning efforts matched to the geographical distribution of target species. However, the Governors' Plan and Fish and Wildlife Plan do not provide enough detail to answer the question of scientific adequacy.

The BiOp and Basinwide Recovery Strategy contain a much more substantive discussion of tributary habitat. The process for recovering tributary habitat relies heavily on a combination of modeling, interagency cooperation, and landscape assessments at the subbasin level. The approach holds promise, but there are many pitfalls. If the EDT modeling effort of NWPPC is able to generate useful first-level subbasin assessments, if action agencies are able to agree upon robust and ecologically meaningful sets of performance standards, if there is adequate habitat and fish population monitoring, and if participating organizations can learn from past restoration failures and recent scientific information, real progress will be possible.

It is doubtful, however, that monitoring will provide quantitative answers about the progress of many tributary habitat restoration projects toward meeting the goals of the BiOp by 2010 . That time period is just too short.

Do the documents in aggregate represent a change in the status quo or a continuation of past efforts?

The greatest difference between the approaches outlined in the documents and past tributary habitat restoration efforts is that the documents place much more emphasis on formulating landscape-based recovery strategies. This means that restoration projects will in principle be chosen on the basis of their overall contribution to recovery within the context of salmon life history needs (preferred habitats, seasonal movements) and the extent of habitat alteration (locations of habitat bottlenecks or high quality refugia) within the subbasin of interest. The ISAB applauds this broad-scale approach.

The documents, for the most part, do not provide details but instead set forth general habitat goals. Whether implementation of tributary habitat restoration efforts under the documents will represent a continuation of past programs or a real change in the status quo will depend on their ability to take advantage of recent improvements in knowledge of salmon life history and watershed processes. The pitfalls of many current approaches are familiar to those who have had 
a long history working in the Columbia River Basin. Consensus on anything related to salmon is nearly impossible to reach, and there is little reason to believe that tributary habitat issues will be any different from the contentious issues of dam breaching and hatchery operations. Agencies will have to achieve a level of communication and coordination that is unprecedented for such a large area, particularly as their mandates may occasionally generate actions that are contradictory.

Habitat performance standards will need to transcend water quality hazard thresholds, the traditional approach, and take dynamic watershed processes into account. Subbasin plans will need to demonstrate a linkage between programs that shows a concern for the entire freshwater life cycle of salmon rather than simply a collection of individual restoration projects. If these pitfalls can be avoided and habitat improvement actually speeds up, and if the Columbia River Basin enters a period of favorable ocean survival, increased adult returns may provide the fish to accelerate recovery of wild salmon populations in tributaries.

Do the documents provide a consistent course of action?

The BiOp, Basinwide Recovery Strategy, and Fish and Wildlife Program outline a consistent course of action for tributary habitat restoration, and all three documents utilize scientific peer review (TRTs, ISAB, ISRP) to provide external quality checks. However, there was relatively little mention in any of the three documents about linkages with ICBEMP or Tribal habitat recovery projects, both of which may be significant depending on location. Coordination among action organizations will be critical to restoration success.

The Governors' Plan appears to be least consistent with the other documents. Although the section on habitat in the Governors' Plan is brief, it is clear that it endorses restoration efforts designed by local organizations (watershed councils, city and county authorities) as opposed to efforts designed by large federal agencies. The Governors' Plan makes no mention of scientific peer review of local strategies. The ISAB suspects this approach will be likely to continue the status quo, and may well be at odds with regional habitat restoration efforts identified in the BiOp, Basinwide Recovery Strategy, and ICBEMP.

Are linkages among strategies for dealing with the 4 H's adequately identified?

Tributary habitat recommendations in the documents, in general, are inadequately linked with recovery strategies in the other Hs. There was little discussion of how habitat restoration would be tied to supplementation, if at all, in most of the documents. The Fish and Wildlife Program does, however, stress the need for supplementation to be linked to watershed condition and to be integrated into subbasin planning. The consequences of putting more water back into tributaries were not clearly linked to mainstem habitat management or water quality issues such as temperature and dissolved gas. The role of salmon carcasses as vectors of marine-derived nutrients in salmon-producing watersheds was not adequately linked to harvest and escapement levels in the documents. Changes in habitat restoration tactics were not related to climate shifts or disturbance factors such as droughts, floods, or wildfires. 


\section{Hatcheries}

Salmon recovery planning within the Columbia River Basin anticipates that hatchery origin salmon and steelhead will continue to play a prominent role both in maintaining harvest and in aiding in wild stock recovery, even though hatchery fish create a paradoxical dilemma for basin salmon management efforts. On one hand they are viewed as providing significant harvest opportunities, while on the other they are asserted to contribute to declines in wild populations through genetic (interbreeding between hatchery origin and wild salmon) and ecological (competition, predation, disease transmission, incidental over-harvest) interactions. Consequently, maintaining harvest of hatchery origin fish while simultaneously attempting to recover wild stocks is controversial. Individually and collectively, the four documents acknowledge the potential problems of using artificial production, yet propose to continue and even expand existing artificial production programs. To overcome that apparent dichotomy, the four documents all state a clear desire to reform the hatchery system. Unfortunately, the institutional structure required to design and implement such reforms does not appear to be fully in place. The Northwest Power Planning Council proposed basinwide hatchery policies in its recent artificial production review (APR) (NPPC document 1999-15). Most of the four documents endorse the APR policies and envision implementing them by using Hatchery and Genetic Management Plans (HGMP's) designed by the National Marine Fisheries Service. However, the details for implementing reforms at a basinwide scale are not yet developed.

\section{Governors' Plan}

The Governors' plan supports recommendations of the APR to significantly modify hatchery management practices in Federal and State hatcheries. Unfortunately, the specific management practices to be modified are not identified. The report endorses reviewing the purposes of each hatchery facility within three years to determine the facility's future role in supporting fish recovery and harvest. This proposed review is consistent with an implementation action proposed in the Council's APR. The report also makes a number of additional recommendations. Regional managers should develop a basin-wide comprehensive supplementation plan, something not in the APR. Certain watersheds should be maintained as wild fish refuges that also would serve as controls for evaluating conservation hatchery efforts. Marking hatchery fish should be used as a means to facilitate a robust harvest program for hatchery fish. Terminal and selective harvests of hatchery fish should be explored. Excess fish produced by hatchery operations should not be harvested if that harvest could result in unacceptable take of ESA listed stocks.

\section{Basinwide Recovery Strategy}

The Basinwide Recovery Strategy summarizes studies that indicate the potential hazards of genetic, ecological, and harvest interactions between hatchery and wild salmon. Qualitative impressions of improvements for listed ESU's from anticipated hatchery reforms are presented and vary throughout the basin from providing considerable benefit for upper Columbia River steelhead to providing little benefit for upper Willamette winter steelhead. The plan concludes that hatchery reform effects cannot easily be estimated. Suggested reforms include developing 
local broodstocks, eliminating inappropriate broodstocks, and minimizing hatchery straying rates. This document anticipates using HGMP's to implement reforms, as well as using captive brood and conservation hatchery programs for emergency interventions for up to 13 populations of steelhead, spring/summer chinook and fall chinook.

\section{Biological Opinion}

The BiOp anticipates off-site mitigation for FCRPS using hatchery programs for the production of salmon and steelhead as outlined in the Basinwide Recovery Plan reforms. Section 9.6.5.4 (page 9-131) provides important guidance on monitoring hatchery fish in relationship to wild stocks and proposes that reforms should conform to NMFS' interim artificial propagation policy (Hard et al. 1992) and conceptual framework for conservation hatcheries (Flagg and Nash 1999). This monitoring section of the BiOp contains some of the clearest guidance for implementing hatchery reforms. There is an acknowledgement that the appropriate reforms needed for specific hatcheries and for the protection of specific wild stocks are largely unknown, and that it will be difficult to ascertain a priori what effects reforms will have. Monitoring and evaluation is a necessary first step in the design of reforms. Actions given in the chapter on reasonable and prudent alternatives using off-site hatchery mitigation call for immediate reforms and modernization of many facilities/programs. Implementing these reforms before appropriate analyses are established appears contradictory to the monitoring section. Section 9.6.3 (pages 9115-119) recommends selective and terminal fishing to maintain harvest on hatchery fish.

\section{Fish and Wildlife Program}

The Fish and Wildlife Program's approach to artificial production consists of several elements. Strategies focusing on the use of artificial production should be consistent with limitations of, and opportunities for, improving specific habitat conditions. Wild salmon refuges, harvest hatcheries, and conservation/supplementation hatcheries are envisioned. Refuges should be located where habitat is intact. Supplementation should be used to rebuild natural runs only in conjunction with habitat improvements, so that eventually the population would become selfsustaining. Supplementation programs should be designed and implemented only within the context of subbasin plans. Harvest hatcheries should be operated only in a manner that does not lead to adverse genetic, ecological effects, or excessive take of listed stocks in mixed fisheries. Artificially produced fish created for harvest should not be produced unless they can be effectively harvested in a fishery. Recommendations and policies of the APR should be implemented. Each hatchery and program should be reviewed within three years to determine consistency with the APR. Annual reporting of progress and a five-year assessment of implementing reforms is proposed. An artificial production committee is recommended to guide reforms and coordinate monitoring and evaluation across the basin. 


\section{Summary}

Do the documents in aggregate represent an adequate response to the problem? Do the documents describe a course of action that is likely to achieve regional goals such as ESA delisting, harvestable fish, and sustainable ecosystems?

The ISAB believes the answer to both questions is no. Little evidence is provided for anticipating that the hatchery reform measures proposed in the APR will improve salmon recovery. We believe caution is warranted in putting too much weight on hatchery improvements until they have been adequately tested and evaluated, but that level of caution is not given in these documents. The documents do acknowledge that a number of problems exist with the way artificial production is being used. Unfortunately, because the magnitude of the problem is unknown, the benefit of implementing reforms is unknown. The intent of the APR policies and anticipated reforms is to reduce or eliminate adverse effects to wild fish from hatchery releases. Only the monitoring portion of the $\mathrm{BiOp}$ acknowledges that monitoring and evaluation is needed to design reforms adequately. Current reform suggestions for hatcheries are largely common sense and are supported by our understanding of the biology of Pacific salmon. The chain of authority that is needed to review the Hatchery Genetic Management Plans that are envisioned as serving to guide reforms and begin the monitoring of performance indicators is not clear.

Institutional mechanisms, including the Council's artificial production committee, are needed for establishing cooperation among State, Federal, and Tribal management efforts. The time frame in the documents for implementing reforms and evaluating their effectiveness seems unrealistically optimistic. The monitoring envisioned by NMFS for wild fish recovery would benefit from including the monitoring of hatcheries for hatchery reform design. Implementing this across state, federal, and tribal jurisdictions will take time. While the aim of reducing the adverse interactions between hatchery and wild stocks is certainly worthwhile, relying solely on containing these hazards is insufficient for managing their risks. Because failures of containment measures are probable, hatchery fish will inevitably have the opportunity to interact with wild stocks. Institutional procedures to detect containment failures and intervene with remedial actions are imperative but as yet not established. Maintaining harvest through selective and terminal fisheries for hatchery fish is a moderately high-risk proposal based on previous experience with anadromous salmonids. Decision makers have not built a mechanism into harvest plans that is designed to deal with any of the myriad inevitable unforeseen straying problems likely to arise.

Do the documents in aggregate represent a change in the status quo or a continuation of past efforts?

The documents represent a continuation and evolution of past efforts. With regard to artificial production this may not be an entirely unavoidable or undesirable approach, at least in the short term. If an acceptable artificial production program is possible, designing or creating it is likely to involve occasional progress with many mistakes. Similarly, abandoning or substantially curtailing artificial production, concluding that it is a failure, will only happen once stakeholders have exhausted their efforts to make it succeed. 
Do the documents provide a consistent course of action?

Yes, but that approach appears inadequate. For example, even though all four documents recognize a need for hatchery reform, none of them provide details describing that reform or plans on how to implement it. The documents all assume that artificial production is quite capable of providing mitigation for habitat loss and that supplementation will succeed in helping to rebuild wild salmon populations. Unfortunately, neither of those critically important assumptions has been verified.

Are linkages among strategies for dealing with the 4 H's adequately identified?

Linkages are not adequately identified. Linkage between harvest hatcheries and harvest level is recognized, but the problems of developing selective and terminal fisheries are not adequately considered. Linkage between habitats and supplementation is acknowledged, but how subbasin planning and habitat modeling will inform decisions on where and how much supplementation is warranted is not clear. The cumulative detrimental effects of hydroelectric operations and other habitat conditions (e.g., water withdrawals) on mainstem habitats and how these effects limit the accomplishments of mitigation efforts using artificial production needs more attention. Based on observations from hatchery returns in the early 1960's, we anticipate that a Pacific Decadal Oscillation regime shift could produce abundant returns of salmon similar to those in 2000 and expected in 2001. Such returns of hatchery fish will undoubtedly create pressure for high harvest levels.

\section{Additional Considerations}

The Basinwide Recovery Strategy, Governors' Plan, BiOp, and the Fish and Wildlife Program present similar strategies for the use of artificial production, anticipating or encouraging expansion of (1) terminal fisheries targeting hatchery fish, (2) selective fisheries through the use of mass marking, (3) supplementation to attempt rebuilding of depressed stocks, and (4) conservation hatcheries to include captive breeding for seriously depressed stocks.

All four documents assume, with little reluctance, that supplementation will succeed in accelerating the desired goal of salmon restoration. They either propose explicitly or at least imply that increasing artificial production is one means to overcome habitat shortcomings. This is an assumption with little supporting evidence. To overcome the risks associated with artificial production, all of the documents call for implementation of reforms in hatchery practices as outlined in the APR. We conclude that there is insufficient detail on how that implementation is to be accomplished, much less on how to deal with the many shortcomings inherent with the APR. The proposed end result is an increased investment in and reliance on artificial production as a viable strategy for salmon recovery. The ISAB believes there are serious limitations to this strategy that are neither examined nor explained by any of the four documents.

Many millions of hatchery-produced smolts have been released to supplement select Columbia River tributaries over the last decade. The ISAB is unaware of compelling evidence that increased natural smolt production or increased natural adult returns have resulted from these efforts. An independent assessment of the past decade of supplementation is overdue. That 
assessment should include a summary of what is known about successes and failures of supplementation attempts outside of the Basin, as well as a thorough investigation of existing evidence from supplementation efforts within the Columbia River Basin. That assessment should also investigate what is known or believed about carrying capacities for juvenile salmon within various parts of the Columbia River System and throughout the different phases of the life cycle. If analyses are inconclusive due to a lack of appropriate past monitoring and evaluation procedures, the ISAB could help by identifying key components of data collection and assessment needed for success. The ISAB believes that it is essential to devise an appropriate large-scale experiment to measure the actual impacts of supplementation programs in the Columbia River Basin.

All four documents explicitly recognize genetic and ecological risks associated with artificial production and acknowledge that past and some current programs continue with high-risk practices. All four documents deal with that issue simply by calling for implementation of the reforms outlined in the APR, and as a consequence, assume that the risks will be minimized. Unfortunately, the APR itself contains few details about what reforms are needed, much less how reforms are to be implemented. This lack of detail is a result of several data gaps. First, there is not a clear understanding of the different types of risks associated with each of a variety of different hatchery practices, e.g., selective breeding that has changed the makeup of originally native-source broodstock versus the use of non-native broodstock as a source for production. In addition, there has not been a good evaluation of the evidence to support the theoretical bases for those risks - at least not within salmonid fishes. Concern over risk is acknowledged in a vague sense, but priorities for dealing with those concerns are not established in practice or policy. The ISAB believes that a clear explanation of the genetic and ecological issues involved, as well as an extensive assessment of the evidence supporting the theory behind the associated risks would provide much guidance for artificial production in the Basin.

Second, the four documents do not map out a clear strategy for reducing the risks associated with artificial production. They all simply rely on the implementation of the APR, which itself lacks a clearly prioritized strategy or method for implementation. Implementing reform requires a roadmap for change and a means of evaluating the relative success in instituting that change, two important components that are currently missing from the APR. A useful roadmap for change would require establishing a clear set of goals and objectives for artificial production, developed hierarchically from subbasin plans upward through a coordinated Basin-wide level. While a subbasin planning process is just now being initiated, we are not aware that coordinated artificial production planning is intended. As a result, that clear set of objectives does not yet exist.

Designing reforms and evaluating their progress toward meeting hierarchically based objectives for artificial production could be gauged by monitoring indicators established for artificial production. This activity is envisioned in the Council's APR. Indicators for artificial production should be designed to measure whether program goals are being achieved and to answer questions of uncertainty regarding artificial production practices. Indicators for evaluating artificial production require collecting standardized primary data through monitoring, calculation of the indicators, and evaluation of the results. Eventually performance standards for these indicators could be established. We do not believe that analysis of existing data is sufficient to establish performance standards for contemplated indicators. Currently the agencies and tribes 
within the basin have agreed upon a generic foundation of indicators for artificial production. Some of these indicators, such as harvest numbers or rates, are fairly straightforward to calculate, although considerable care is needed to ensure that primary data collections are sufficient to calculate the statistics. For many of the conceptual generic indicators, such as comparisons of life histories between wild and hatchery fish, no established indicators exist. For these, design of indicators from primary data is required. The ISAB urges completion of the provincial and subbasin planning efforts, as well as the timely initiation of monitoring, so that an adequate and usable set of indicators and their performance standards can be devised to assist in guiding policy, suggesting important research, and creating public confidence in artificial production efforts. 


\section{Harvest}

Harvest strategies are generally consistent among the recovery documents, but the topic of harvest definitely receives the least attention of the H's in recovery planning. The latter follows for two reasons: each paper notes recent major reductions in exploitation on these stocks, to the extent that additional reductions have marginal value to most stocks; and, none of the lead agencies have a direct role in annual fishery management actions. As summarized in the Basinwide Recovery Strategy, regulation of ocean harvest occurs pursuant to the MagnusonStevens Fisheries Management and Conservation Act and the Pacific Salmon Treaty, and management of in-river harvest occurs under the auspices of the federal court in U.S. v. Oregon. In addition, NMFS or USFWS must authorize any harvest of ESA-listed fish. Even the new Pacific Salmon Treaty agreement was reviewed by the NMFS under section 7 for consistency with the ESA. In its biological opinion of November 1999, NMFS determined that the agreement met the ESA requirements. However, while the treatment of harvest may be limited, the importance of harvest management to recovery is paramount for the immediate short-term survival of populations and reflects the degree of change that has already occurred in the fisheries and fishing communities. As stated in the Governors' Plan, "Salmon fishing has decreased to a level that represents a mere fraction of what once occurred." Maintaining these reductions in harvest impacts is a core assumption of recovery planning.

Consideration of harvest in these papers can be summarized as five major points:

- The extent of recent harvest rate reductions has been so extensive on most stocks that further reductions will not likely yield further major benefits (most harvest impacts on listed fish now occur in treaty-protected fisheries);

- Each paper recognizes the federal government's trust obligation to provide meaningful treaty harvest, both today and in the future (best described in the Basinwide Recovery Strategy ${ }^{1}$ );

- Each paper notes a reliance on the development of more selective fishing methods to provide for sustainable fishing opportunity while protecting the listed fish and allowing harvest expansion where feasible;

- The linkage between hatchery production, harvest, and recovery of natural production of salmonids is clearly acknowledged and is the major feature of integrated production planning in the 2000 Fish and Wildlife Program; and

- The specific example of developing selective fisheries for mass-marked hatchery fish is noted.

Concerning the specific documents, each provides a few specific additional comments but the most detailed treatment of harvest is contained in the Basinwide Recovery Strategy.

\footnotetext{
1 “...the Strategy recommends an acknowledgement that there is an "irreducible core" of tribal harvest that is so vital to the treaty obligation that the federal government will not eliminate it." "Where tribal fishing is involved, we recommend accepting a level of risk that is greater than the biology might strictly imply." (page 55, Vol. 1, Basinwide Recovery Plan)
} 


\section{Basinwide Recovery Strategy}

A few excerpts from the report encapsulate the treatment of harvest by the Federal Caucus (see sections 3.3 Harvest Actions, Volume 1; and Chapter 2, Volume 2, Harvest Element...).

"The objectives of the harvest strategy are to buy time for other recovery programs and measures to take effect; preserve at least some fishing, particularly for tribal fisheries provided that doing so does not undermine the overall recovery effort; fully implement the 1999 Pacific Salmon Treaty Agreement; and develop a sustainable fishing strategy for the long term, with particular emphasis on selective fisheries." (Page 53-54, Vol. 1)

"Therefore, the Federal Caucus recommends constraining harvest rates on listed salmon and steelhead at or, if necessary and effective for survival and recovery, below their currently reduced rates for 10 years or until the status of listed fish can support harvest increases. In addition, for those ESUs where harvest remains a significant source of mortality, further reductions of incidental take of listed species will be pursued through additional measures, possibly including but not limited to such measures as license buy-backs, gear changes, additional time and area restrictions, and selective fishing." (Page 55, Vol. 1)

"Over the long run, harvest constraints cannot be relied on to solve the fundamental problems that cause natural salmon productivity to decline." (Page 54, Vol. 1)

Concerning assumptions of the supporting analysis, the Basinwide Recovery Strategy states that "productivity rates identified by CRI as necessary to achieve survival and recovery account for harvest impacts at current levels." The potential for additional reductions in harvest impacts through development of more selective fishing techniques was not factored into these analyses. To assess compliance with the harvest strategy, the performance standards will be specific harvest constraints and the fishery plan as described in Volume 2 for fishery group (ocean and freshwater) and listed ESU. To assess compliance requires that ocean exploitation rate by stock and terminal harvest rates can be measured with sufficient accuracy and precision to compare against the recent values of these parameters. However, one type of selective fishing (markselective fisheries) is also a potential threat to the ability of management agencies to assess compliance with the performance standards. A mark-selective fishery involves the selective retention of mass-marked hatchery fish (marked by removal of the adipose fin) and release of unmarked fish including fish produced naturally and unmarked hatchery fish. Unfortunately, the selective retention of marked fish violates the fundamental assumption of the coded-wire tag (CWT) program that has been the basis of chinook and coho management for the past 25 years. Further, maintaining the viability of the coded-wire tag program is a commitment embodied in the Pacific Salmon Treaty. While the Basinwide Recovery Strategy notes the potential value of mark-selective fisheries, it also notes the risks to assessment and management capabilities:

"Furthermore, the statistical viability of the original CWT program relied on the assumption of randomness - a fish with a CWT was no more or less likely to be 
killed in a fishery than one without the tag. A selective fishery, by definition, is non-random. Consequently, the ability of the CWT program to provide statistically reliable fishery and stock-specific information is threatened." (Page 49, Vol. 2)

\section{Biological Opinion}

The Biological Opinion largely defers consideration of harvest to the Basinwide Recovery Strategy, except for section 9.6.3 Harvest Measures. As stated, "this opinion addresses the operation and management of FCRPS, not harvest."

"Harvest management is not within the authorities of the Action Agencies; therefore, additional constraints cannot be imposed on fisheries by this biological opinion. Instead, this section outlines harvest measures the Action Agencies can facilitate to meet offsite mitigation goals for hydrosystem impacts and measures that may further reduce the take of listed species." (Page 9-143).

Under consideration of Reasonable and Prudent Alternatives and to avoid jeopardy, harvest reform is defined broadly (Section 9.6.3.2). Harvest reform "includes implementing various kinds of harvest management reforms such as selective fishery management strategies (e.g., mark-selective fisheries), developing and applying alternative fishing methods and gear types, and creating or expanding fishing opportunities in areas or at times when listed fish are not present."

This section also comments on the development of mass-mark selective fisheries, adding three important comments (page 9-145):

- "Mark-selective fisheries are not recovery tools, but rather means to allow fishing to continue."

- "Existing management and assessment tools, including various models, analytical methods, procedures, and associated databases, will also have to be refined and/or replaced."

- "Realizing the full potential of selective fishing depends on a number of elements, both technical and policy-level. Before the strategy would work in Tribal fisheries, social, economic, and cultural impacts would have to be addressed in ways the Tribes support."

To develop and implement new selective fisheries, the BiOp specifies five actions (Actions 164168) committing the Action Agencies to:

i) Assist in the development, testing, and deployment of selective fishing methods;

ii) Work with other agencies to develop and implement methods and analytical procedures to estimate fishery and stock-specific management parameters (e.g., harvest rates);

iii) Implement and/or enable changes in catch sampling programs and data recovery systems;

iv) Develop improved methods for estimating incidental mortality in fisheries (within a timeframe necessary to make new marking and selective fishery regimes feasible); and 
v) Develop methods for crediting harvest reforms, and survival benefits they produced, towards FCRPS offsite mitigation ${ }^{2}$.

\section{Fish and Wildlife Program}

The primary strategy stated in the Program (section III D.5) is to "assure that sub-basin plans are consistent with harvest management practices and increase opportunities for harvest wherever feasible". The Program places a strong emphasis on sub-basin planning of fish production and integration of harvest management plans/capabilities with spawning escapement goals established for each species or stock, and hatchery production planning. Sub-basin plans are to determine the likelihood that adequate numbers of adults will return to "assure reproductive success and meet sub-basin goals for the next generation." The strategies will also consider how to modify harvest practices if more adults are required or if there exists an opportunity for increased harvest, provided the harvest does not negatively impact other listed fish. Again, the Program identifies the development of more selective fisheries to provide for additional harvest.

Further, the Council recommended six "practices" for harvest management, and will encourage the region's managers to adopt them (page 31, section III D5):

- Maintain an open and public process, allowing public observation of harvest and allocation discussions and timely dissemination of harvest-related information in a publicly accessible manner.

- Integrate harvest management to assure that conservation efforts made in one fishery can be passed through subsequent fisheries.

- Manage harvest to ensure the risk of imprecision and error in predicted run size does not threaten the survival and recovery of naturally spawning populations.

- Monitor in-river and ocean fisheries and routinely estimate stock composition and stockspecific abundance, escapement, catch and age distributions.

- Manage harvest consistent with the protection and recovery of naturally spawning populations.

- Biennially solicit scientific peer review of harvest management plans and analyses, starting in January 2002.

\section{Governors' Plan}

Three key elements describe the regional approach envisaged in this Plan. Their suggested goal is to protect and restore production of salmonids and other aquatic species to sustainable and harvestable levels that meet the requirements of the ESA, the Clean Water Act, the Northwest Power Act and tribal rights under treaties and executive orders. Restoration, however, should occur while taking into account the need to preserve a sound economy in the Pacific Northwest.

\footnotetext{
${ }^{2}$ Action 168 (item v above) is similar to the positive incentives clause in the Chinook Annex of the 1999 PST Agreement that allows reduction of incidental fishing mortality to be transferred to catch, up to $50 \%$ of the adult equivalent savings may be taken as catch following review by the Chinook Technical Committee.
} 
Their preferred objective would be to benefit salmon through strategies and actions that emphasize and build upon natural processes.

These statements are certainly similar to the other documents but may be interpreted as a stronger statement to restore harvest through natural production processes. The Governors' state that they are committed "to support a recovery approach designed not only to achieve ESA delisting levels but also to rebuild the runs to levels that support treaty and non-treaty harvest." However, they also acknowledge that restoration should not occur at any cost. The Governors' note what they called a "Fifth H", that being the impact of restoration on humans.

Concerning harvest specifically, this Plan comments on ocean harvest and harvest in the Columbia and Snake rivers. Ocean harvest has been addressed for ten years through the Pacific Salmon Treaty that has for the first time implemented an abundance-based ocean harvest regime. They note that additional reductions in ocean impacts may be achieved through more selective fishing, a license buyback program to reduce the current excess fishing capacity, and reduction of salmon bycatch in other fisheries. Within the Columbia system, the Governors' support continuing current levels of tribal ceremonial and subsistence harvest but suggest that further reductions may be possible in commercial and non-treaty sport fisheries. Harvest rates in the latter fisheries should "be consistent with ensuring survival of the species and providing for their eventual recovery when combined with recovery actions in other sectors." To achieve further reductions, they supported increasing the selectivity of mainstem harvest, research to develop better selective fishing techniques, and financial incentives.

The Plan also notes the need to modify hatchery production so that excess fish are not being produced where they cannot be harvested. But in other paragraphs, the Governors' also promote the mass-marking of hatchery fish "to facilitate a robust harvest program for hatchery fish that pose threats to ESA-listed fish", and the development of new terminal fisheries below Bonneville Dam and in Zone 6 (fishing area) to replace lost mainstem fishing opportunities.

The Governors' also supported strengthening law enforcement programs to ensure accountability and reduce illegal catch, and recommended changing existing sport fishing restrictions to concentrate on species that prey on, and compete with, salmon for food. Sport fishing regulation changes also should strive to minimize effects of exotic species on native species.

\section{Summary}

Do the documents in aggregate represent an adequate response to the problem? Do the documents describe a course of action that is likely to achieve regional goals such as ESA delisting, harvestable fish, sustainable ecosystems?

The documents do not directly address harvest but rather assume the continuation of changes in harvest management that evolved over the past 10-20 years, depending on the fishery and status of stocks. These changes include substantial reductions in the total exploitation rates on naturally spawning salmonid populations, fishing regimes responsive to changes in abundance, and management of total fishing mortality (i.e., catch plus associated incidental mortality). In general, the agencies preparing these documents are not responsible for these changes and do not 
regulate fisheries, with notable exception of NMFS or USFWS responsibility for jeopardy evaluations on ESA-listed fish. Consequently, these agencies cannot guarantee the continuation of the harvest rate reductions assumed in their assessments, but it is unlikely that rates will increase if the productivity of the natural populations remains depressed. However, if productivity increases, ocean harvest rates on some chinook and coho stocks will increase within the PST, and we can expect substantial pressure to increase terminal harvest rates on natural and hatchery populations. Sensitivity of recovery to variation in total exploitation rates can be assessed but introduces a second major source of uncertainty.

Each document supports the development of more selective fishing techniques and, in particular, the development of mass-mark selective fisheries. The implicit assumptions in these techniques are that the total mortality associated with these catch-and-release fisheries is less than the mortality in retention fisheries, and that the resulting harvest rate will be sustainable by naturally produced salmonids. Intuitively these seem obvious ... but they may not be (as noted in Volume 2 of the Basinwide Recovery Strategy). For example, what are appropriate mortality rates to apply to released fish, how variable are these rates between fisheries, seasons, stock, etc., what is the probability of multiple catch-and-release events per fish and what are the cumulative mortality rates? For severely depressed or unproductive stocks, what is the maximum exploitation rate that can be sustained and what is the cumulative mortality rate across all sources of mortality during its life cycle, can it sustain the mortality associated with even selective fisheries? No one can argue with the desirability of fishing more selectively and minimizing the mortality on listed-fish, but the potential benefits of selective fishing must be evaluated objectively and cautious expectations maintained until their utility can be assessed. Our goal is to restore healthy natural spawning populations. This requires controlling mortality throughout the life cycle of these species, not simply during one catch-and-release event in a new selective fishery.

A related concern is the development of mass-mark selective fisheries and their potential impact on the CWT program. The CWT program is essential to the estimation of total exploitation rates in fisheries by age and stock and is the only means to measure these parameters. Yet continuation of the current rates are the performance standards stated in the Basinwide Recovery Strategy. At this time, we are uncertain whether the viability of the CWT program can be maintained if mark-selective fisheries are implemented. However, the loss of information will depend on the magnitude and location of the selective fishery and our ability to sample nonselective fisheries before and/or after selective fisheries. Further, the impact of this loss will differ depending on the status of the stock and the estimated exploitation rates. For example, if the rates are low and the stock is recovering then the loss of information maybe an acceptable cost of the recovery plan. Alternatively, if exploitation remains moderate and the stock is not recovering, then the loss would be more significant. Further, the loss of information may be unacceptable to other fishery management processes outside of the Columbia River system. Obligations of the Pacific Salmon Treaty require that each country assess the aggregate exploitation rates over all fisheries and to ensure that this aggregate value is less than a maximum value stated in the Chinook Annex. It will be the responsibility of each country to meet this requirement before additional harvest restraints could be requested through the Pacific Salmon Commission. 
Do the documents in aggregate represent a change in the status quo or a continuation of past efforts?

As discussed above, the answer to this is that the documents do both. The general assumption that current reductions in harvest impacts will be maintained is a continuation of past changes. The development of more selective fishing techniques is a continuation of emerging ideas, but is a significant change from the status quo. This change, however, has a number of concerns associated with it that have not been fully discussed in these documents.

Do the documents provide a consistent course of action?

Yes, as noted above, there is a high degree of concordance between the four documents.

Are linkages among strategies for dealing with the 4 H's adequately identified?

Harvest is only one source of mortality in the life cycle of a listed population. The life cycle analyses and the CRI analyses are appropriate means to integrate all sources of mortality during the life of these fish. More in-depth consideration of two issues could have strengthened these discussions of harvest. The extent of fishery impacts sustainable by a stock is determined by its productivity in the existing environment and the status of the spawning population size. To assess the appropriateness of harvest impacts for recovery requires the establishment of spawning escapement goals for each production unit (group of spawning populations), prediction of adult returns expected in the next generation, and a management plan for harvesting surplus returns or harvest restraints to increase the spawning population sizes. The Fish and Wildlife Program calls for the development of these production plans (subbasin plans) but the empirical basis for these assessments in the basin is believed to be quite limited. Secondly, the ISAB is concerned about the identification of mass-mark selective fisheries as a harvest tool without consideration of the potential ecological interactions between hatchery and naturally produced fish. Mass marking of hatchery fish and the development of selective fisheries to utilize this production provide an incentive for maintaining large-scale production of hatchery fish. However, what is not considered in this plan is the potential for ecosystem effects associated with the continued release of large numbers of hatchery-produced fish. 


\section{Models, Monitoring and Evaluation}

All of the documents expect that monitoring will provide data that allow evaluation of whether or not the goals and objectives of the strategies are met. The strategies include the realistic expectation that monitoring and evaluation will identify when performance standards are being met and, in general, when unforeseen problems arise. However, an implicit and sometimes explicit unrealistic expectation of monitoring is found in all of the documents. For example, the Governors' Plan states “....standards should be crafted, wherever possible, in such a way that if improvement is not achieved, the performance standard [monitoring data] would be useful in identifying the problem." The first of this sentence is a valid expectation of classical trend monitoring. The second part implies the hope that monitoring data will identify when a performance standard is not met, and that the same data will also help solve the problem. Unfortunately, strict monitoring programs are rarely able to meet this expectation.

Fortunately, all of the documents also implicitly or explicitly call for research to accompany a monitoring program. Evaluation (including modeling) then implies the combined analysis of monitoring and research data.

\section{Scope of Planned Temporal and Spatial Monitoring}

Aggressive long term monitoring of the hydropower system, harvest, and hatcheries is implied in all of the documents. However, the documents avoid using the words "long term biological monitoring" as if there is a reluctance to endorse or commit to indefinitely monitoring habitat and fish populations. However, all the documents recognize the need for long term monitoring of biological resources to evaluate performance standards, identify the existence of problems, evaluate the results of management actions, and evaluate the results of individual projects. The need for long term biological monitoring will not go away even with recovery of endangered stocks.

The documents differ on the planned spatial extent of monitoring. The BiOp and Basinwide Recovery Strategy would seem to limit monitoring primarily to the current ESUs and habitat used by threatened and endagered species, while the Governors' Plan would include habitat potentially available to anadromous species above Hells Canyon, Chief Joseph, and Grand Coulee dams. The Fish and Wildlife Program deals with the entire basin with the exception of Canada, Wyoming and Nevada.

\section{Models and Data Gaps}

The development of models sometimes gets ahead of the supply of data to assess the reliability of the models' predictions. In this case, the credibility of the science and model predictions may be undermined. The Fish and Wildlife Program contains a far-reaching plan for use of a scientific model for decision-making - the EDT expert system. This model will be used to guide project funding decisions by identifying which sets of interventions, primarily habitat restoration and protection activities, and artificial production, are believed to be most likely to result in higher salmon productivity for a given watershed. Because this model is an expert system that 
has not yet been calibrated for its predictive power, the degree of validity of its results is unknown. The use of these results for current decision-making is nonetheless legitimate, if there is nothing better available for the purpose, as the ISAB has explained in its recent report on modeling (ISAB 2001-1). Still use of such a model constitutes a calculated risk, and the magnitude of the risk could be calculated more precisely if some statistically rigorous quantification of the validity of the EDT model were done. Such validation of EDT should be a high priority effort, and carried out as soon as possible. The need for validation testing of EDT should be an important organizing factor in the overall design of the monitoring program.

The NMFS use of models in the BiOp and Basinwide Recovery Strategy is of a more classical scientific nature, and has exhibited some noteworthy strength. Comparatively, the models used have been refreshingly simple, and their development, justification, and relationship to data has followed an approach of mainstream scientific method. Ideally, the same model would be used from selection of Reasonable and Prudent Alternatives to evaluation of recovery actions. However, different models with different assumptions, simplifications, and approximations have been required to get past data gaps.

\section{Institutional Cooperation and Funding for Monitoring}

All documents agree that success of a monitoring and evaluation program for biological resources is dependent on institutional cooperation, however, the only major commitment for funding is in the Council's Fish and Wildlife Program. The Basinwide Recovery Strategy states, "Implementing this ambitious monitoring program will require an extraordinary degree of coordination among an enormous number of regional management agencies."

\section{Storage and Retrieval of Data and Metadata}

All documents agree on the need for access to primary data and metadata collected in the planned research, monitoring and evaluation. The ISAB endorses the Fish and Wildlife Program commitment to "...initiate a process for establishing an Internet-based system for the efficient dissemination of data for the Columbia River Basin. This system will be based on a network of data sites, such as Streamnet, Northwest Habitat Institute, Fish Passage Center, Columbia River Data Access in Real Time (DART), and others, linked by Internet technology." Similarly, the Basinwide Recovery Strategy states that "... data collection will be conducted using standardized protocols, and the data recorded and managed in a regional database."

The documents recognize the need for elimination of duplication of effort. The Fish and Wildlife Plan includes “...2) identify who will do the evaluation and on what schedule; 3) explain what kind of independent review will be incorporated if the main part of the monitoring and evaluation will be done by a main participant in the plan implementation; ...". The Basinwide Recovery Strategy goes one step further and includes plans for publication of results in the peer reviewed scientific literature. The documents recognize that the key to elimination of effort in the evaluation/modeling stage and trust in the results is independent peer review. 


\section{Indicator Variables and Sampling Designs for Monitoring}

The four documents correctly identify the need for a successful long term monitoring program, but only the outline of a blueprint for monitoring is given. The documents do not include the crucial details on how to scale up to the next level of a basinwide monitoring and evaluation program.

\section{Monitoring of Harvest}

One of the pervasive common elements of the documents is a hope that the move toward selective fisheries will be effective as a way of trying to accomplish recovery of wild stocks and harvest of surplus hatchery runs. The Basinwide Recovery Strategy recognizes that major and expensive changes are going to be required to monitor harvest rates with the introduction of selective fisheries. This fact is recognized by some of the authors of the documents, but naïve statements are found elsewhere to the effect that measurement of harvest rates and escapement are straightforward, and are well developed.

\section{Monitoring of the Hydropower System}

Monitoring of the hydropower system is appropriately called for throughout the plan, to evaluate a long list of performance standards.

\section{Monitoring of Hatcheries}

There is general agreement among the documents that performance standards for hatcheries should be aggressively monitored, but it is not yet clear exactly what will be monitored, or how the results of the monitoring will be analyzed to determine whether "hatchery reform" has been successfully implemented.

\section{Governors' Plan}

The Governors' Plan calls for an aggressive monitoring and evaluation plan including monitoring and evaluation of habitat potentially available to anadromous species above Hells Canyon, Chief Joseph, and Grand Coulee dams. The need for cooperation among States, Tribes, and Federal Agencies for monitoring and evaluation is recognized by the Governors' Plan, but it stops short of committing the States to funding or resources for additional field monitoring or evaluation. Responsibility for actual monitoring and evaluation of recovery plans seems to be squarely placed on the Council and BPA in the recommendation, "Specifically, we recommend that the Council: Prepare an Annual Accountability Report: To better understand Bonneville's expenditures in a basinwide context, and to improve accountability to the ratepaying public,..." 


\section{Biological Opinion and Basinwide Recovery Strategy}

The documents acknowledge that there are uncertainties whether the proposed Reasonable and Prudent Alternatives will suffice to alleviate Jeopardy. The documents propose that aggressive monitoring be put in place to determine, by identified dates, whether the standards have been met.

Monitoring and evaluation of the effect of the hydropower system on anadromous fishes are called for, to evaluate a long list of performance standards. Also, strategies for additional needed monitoring and evaluation of the biological systems are most clearly spelled out in the Section 2.2.11 of the BiOp and Section 7 of the Basinwide Recovery Strategy. These sections contain the same table and much of the same text. Although necessary details are not given, the vision for the design of monitoring and evaluation is appropriately hierarchical where data will be collected at three tiers of increasing detail. Tier 1 (establish current range and future changes in range of anadromous fish and broad environmental conditions every 3-4 years) and Tier 2 (establish a more detailed picture of salmon abundance and trend and environmental conditions annually on a statistical sample of sites) are classical expectations of monitoring and go under various names such as: inventory monitoring, status monitoring, baseline monitoring, or trend monitoring (Bisbal 2001). Tier 3 (effectiveness monitoring) crosses over into "research." In Tier 3 , more detailed data are called for to determine cause-effect relationships between management actions and salmonid populations responses.

These strategies seem to rely primarily on the cooperation of other agencies and the Council's Fish and Wildlife Program for funding of monitoring and evaluation as indicated in the quote "The Strategy also commits the agencies responsible for the federal hydropower system to fund habitat, harvest and hatchery actions to mitigate for unavoidable mortality in the hydropower system, and to an aggressive monitoring and evaluation program to test assumptions, measure performance and reduce uncertainties over time."

\section{Fish and Wildlife Program}

The Council's Fish and Wildlife Program concentrates primarily on monitoring and evaluation of individual projects funded by BPA. The expectation is that data from the individual projects will filter forward to provide information for monitoring and evaluation of attainment of goals and performance standards at the subbasin, province and basin levels.

The Fish and Wildlife Program has a broad role for research with the expectation that it "... identifies key uncertainties for this program and its biological objectives and the steps needed to resolve them. The plan will identify major research topics, including ocean research, and establish priorities for research funding." Monitoring and evaluation then includes the effectiveness of research to resolve key uncertainties.

The Fish and Wildlife Program recognizes the need for cooperation in establishing basinwide monitoring and evaluation and intends to "... initiate a process involving all interested parties in the region to establish guidelines appropriate for the collection and reporting of data in the Columbia River Basin." 


\section{Summary}

Do the documents in aggregate represent an adequate response to the problem? Do the documents describe a course of action that is likely to achieve regional goals such as ESA delisting, harvestable fish, and sustainable ecosystems?

The documents do not represent an adequate response with respect to monitoring. They correctly identify the need for a successful long term monitoring program, but only provide the outline of a blueprint for monitoring. Successful monitoring implies that monitoring will be implemented on a sufficient scale, spatially and temporally, to deliver a large enough number of measurements of a specified precision to answer a question that is being asked. The documents fall short of identifying the amount of monitoring that will be necessary to obtain effective answers, and they do not specify a design to ensure that implementation is efficient. Furthermore, successful implementation will require the extreme level of cooperation called for, including give and take by all concerned. To be successful in a cooperative program, the States, Federal Agencies, and Tribes would need to reallocate staff and resources to a unified monitoring program that will meet the needs identified in the four documents. Unfortunately, the region has not had much success achieving the required level of cooperation because of disagreements over details.

The ISAB encourages the individuals who may undertake the next level of planning to review the lessons learned in monitoring for abundance and distribution of coastal coho in Oregon and Northern California. Based on the review of current monitoring programs by the Independent Scientific Review Panel (ISRP) in the Columbia River Basin, many of the pitfalls in the original coastal coho salmon monitoring plan are still present in the Basin.

Models played a pivotal role in the decisions of the past year. The conclusion of Jeopardy is convincing, but the selection of Reasonable and Prudent Alternatives, and the evaluation of the adequacy of the recovery actions are less secure, mainly for lack of necessary data. The Council's use of the EDT model has the potential to bring a welcome degree of coordination to the portfolio of projects funded by the Council and BPA. What needs more development in the use of EDT is a linkage to monitoring and research that will test the reliability of the expert opinion upon which EDT is based, and provision of a feedback loop that updates the EDT knowledge base with the results of that testing.

Do the documents in aggregate represent a change in the status quo or a continuation of past efforts?

The documents represent a change in the status quo in that more emphasis is being placed on monitoring and evaluation of management actions for improvement of tributary habitat for anadromous species (in particular for the threatened and endangered ESUs) and in the effects of hatchery produced fish on wild stocks. In general, more emphasis is being placed on monitoring of reproductive performance of wild stocks throughout the Columbia River Basin, i.e., monitoring and evaluation of fish in and fish out. 
With respect to harvest, hatcheries and hydropower, the documents present a continuation and evolution of past efforts in monitoring, evaluation and modeling.

\section{Do the documents provide a consistent course of action?}

Basically, the documents are consistent in their call for aggressive monitoring and evaluation of management actions aimed toward recovery of threatened or endangered ESUs, and to support a sufficient abundance of anadromous salmonids to allow increased harvest. The ISAB suggests that Columbia River Basin managers (1) start with the present monitoring of harvest and the hydropower system, and add the first two tiers of the hierarchical plan identified in the BiOp and Basinwide Recovery Strategy for threatened and endangered fish species (including resident fishes) and their potential habitat, (2) continue the Council's call for effectiveness monitoring of projects in the Fish and Wildlife Program consistent with Tier 3 monitoring in the BiOp and Basinwide Recovery Strategy, (3) implement the recommendations for monitoring of hatcheries called for in the ISAB review of performance standards for artificial production, and (4) reevaluate the harvest and hydropower monitoring programs.

Are linkages among strategies for dealing with the 4 H's adequately identified?

The documents are correct to call for monitoring and evaluation of certain linkages, e.g., effect of naturally spawning hatchery fish on wild populations, effect of habitat improvement actions on returning numbers of spawners, effects of supplementation on recovery of wild stocks, etc., although important unresolved details remain. In general, the documents continue to call for independent monitoring of the Hs, i.e., monitor harvest, monitor habitat, monitor hatcheries, and monitor the hydropower system, in the hope that effects of the linkages among the Hs can be evaluated. Examples of specific monitoring needs that have not received adequate planning include monitoring the effect of selective fisheries on wild stocks, monitoring natural survival rates of adult chinook in the ocean, and development of a permanent plan for monitoring of downstream survival of juveniles. In fairness to the documents, it is unrealistic to expect them to thoroughly monitor and evaluate all linkages between the Hs. To adequately monitor and evaluate all linkages would create a 'Grand Experiment' to understand everything about anadromous fishes and their habitat, a worthy goal, but one that is hardly realistic. Given this realistic limitation of feasibility, it becomes all the more important to develop a concrete plan with a statistical design, to ensure that the monitoring that is undertaken does adequately address the priority questions. 


\section{Climate, Hydrology, and Water Resources}

Climate is defined as "average weather", i.e., the statistics of weather over a long period of time, for instance the long-term monthly average July maximum temperature, or total January precipitation, or the frequency of cloudy days in September. While the vagaries of climate have often seemed random and unpredictable, recent advances in climate science point to a handful of regularly occurring hemispheric-scale patterns that impose some order on the climate system. In the Pacific Northwest, the El Niño/Southern Oscillation (ENSO), and the Pacific Decadal Oscillation (PDO) strongly affect climate on time scales of several years in the case of ENSO, and one to several decades in the case of PDO. ENSO is driven by sea surface temperature (SST) anomalies in the equatorial Pacific, while the PDO is driven by SST anomalies in the north Pacific. These phenomena tend either to amplify or mitigate cold-wet and warm-dry periods, which strongly affect various manifestations of climate (both on land and ocean) in the Pacific Northwest. The strongest deviations from "normal" conditions have occurred when the two phenomena act in concert, particularly when an El Nino event occurs during the warm phase of PDO (see Figure 2).

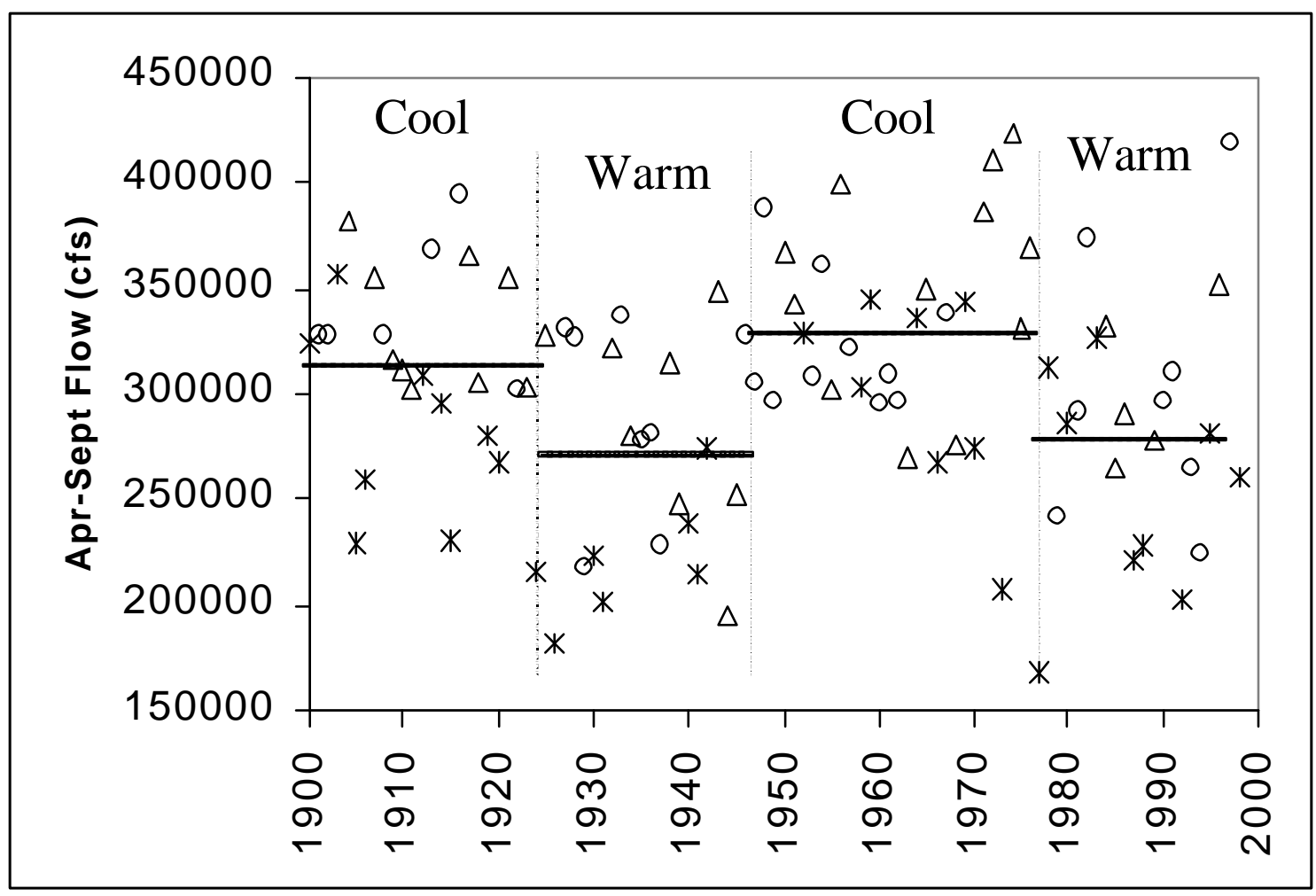

Figure 2: April-September Average Naturalized Streamflow for the Columbia River at The Dalles. Solid horizontal lines are PDO phase average, crosses are El Niño years, circles are La Niña years, triangles are ENSO Neutral years. (Figure adapted from Hamlet and Lettenmaier (1999a)) 


\section{$1858-1998$}

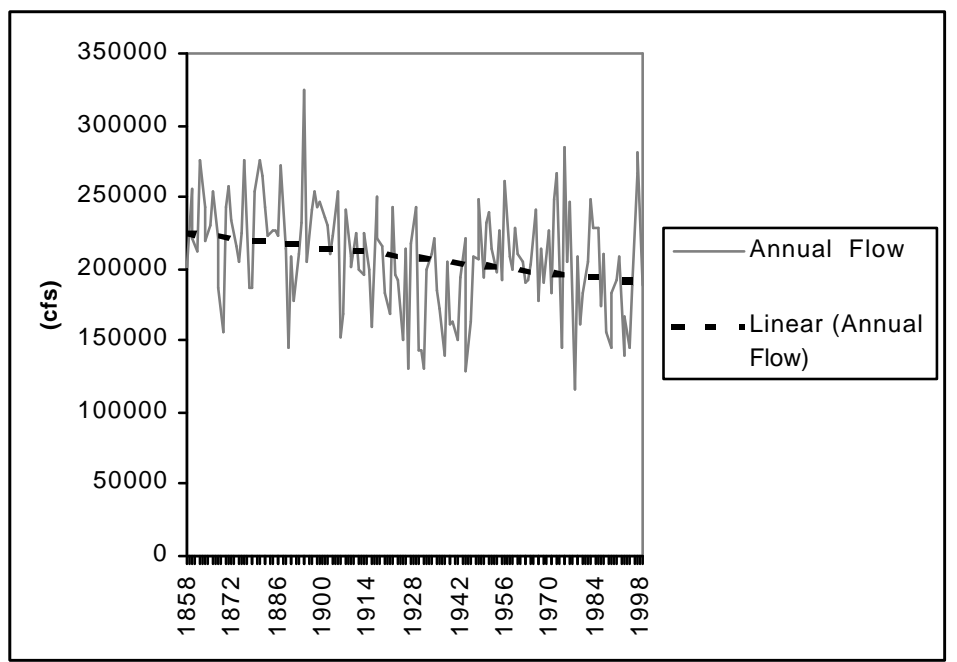

\section{0-1998}

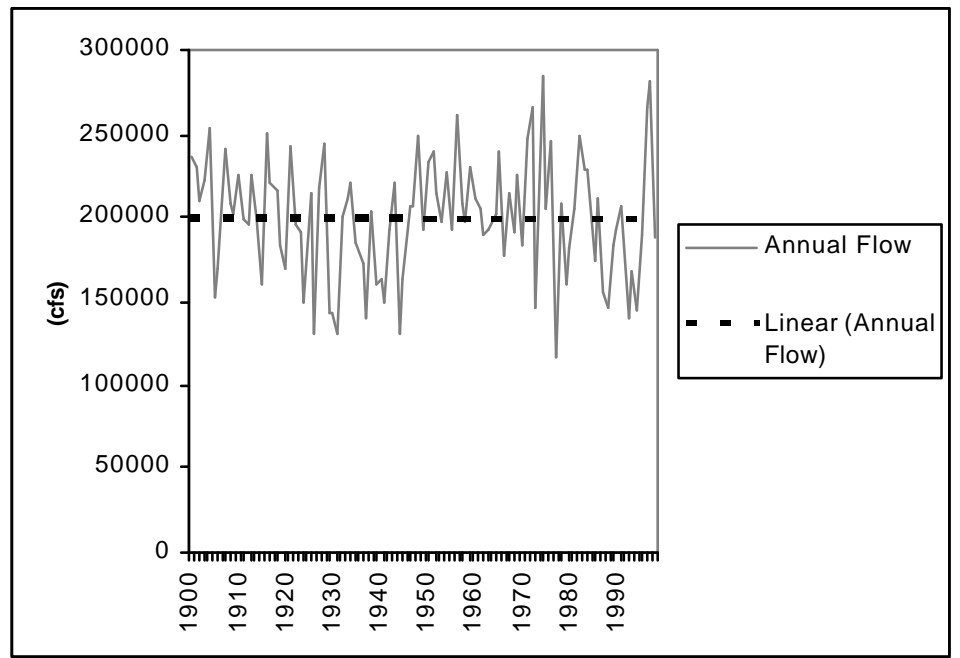

Figure 3: Long-term trends in Columbia River streamflow at The Dalles, 1858-present (upper), 1900-present (lower). (Data for 1858-1928 courtesy of David Jay and Pradeep Naik, Oregon Graduate Center, and for 1928-1998 courtesy of the Bonneville Power Administration)

The reverse is true, although to a somewhat lesser extent, for cold PDO and La Niña. Figure 2 shows how strongly these two modes of variability affect Columbia River streamflow. Most of the lowest flow years of record have occurred in the warm-dry state. While ENSO is now predictable with fair accuracy at least a year in advance, PDO changes, like the wellacknowledged one that occurred about 1977, are not currently predictable, except by persistence (that is, assuming next year's state will be the same as this year's). There is currently some evidence that PDO may have shifted from the post-1977 warm-dry state to cool-wet within the last five years, but there is as yet no strong consensus. Superimposed on the natural variability in climate and streamflow are long-term changes, now increasingly attributed to anthropogenic causes, such as burning of fossil fuels. In the Columbia River basin, annual average temperature has warmed about one degree $\mathrm{C}$ over the last century, a trend that is quite consistent across the 
region. On the other hand, changes in precipitation over the same period are less apparent. In the historic streamflow record (when adjusted for the effects of irrigation withdrawals and reservoir storage), there is an apparent downward trend over the last half of the $19^{\text {th }}$ century, but little or no trend since 1900 (Figure 3).

Projections by climate models (so-called General Circulation Models, GCM, of the coupled atmosphere-ocean-land system) all predict warmer conditions over the next century. The amount of warming that is expected over the next 25 years is comparable to that which has been experienced in the Columbia River Basin over the last century. Estimates of the amount of warming vary greatly, from as little as one or two degrees $C$ over the next 50 years to over five degrees $\mathrm{C}$. There is less consensus on precipitation, and even the direction of change is not clear although there is a weak consensus for a modest increase in precipitation (10-20 percent annually). Even given this range of scenarios, important information about likely effects on streamflow can be extracted. Using simulation modeling methods to construct hydrologic scenarios corresponding to several of the GCM projections for the Pacific Northwest, results like those shown in Figure 3 were produced. Figure 4 shows the resultant effects on snow accumulation in the Columbia River Basin. The overall effect in all such simulations is similar winter flows are increased due to more rain and less snow, the seasonal peak occurs earlier, and spring and fall flows are reduced relative to the current climate. Of course, specifics vary depending on the particular climate scenario, for some of the scenarios increased evaporative demand is more or less balanced by increased precipitation. The change in the time of peak flow depends on the amount of warming; the greater the warming the earlier in the year the peak occurs. More details are included in the Water Sector, and Pacific Northwest Regional, reports of the 2000 U.S. National Assessment of the Potential Consequences of Climate Variability and Change. 


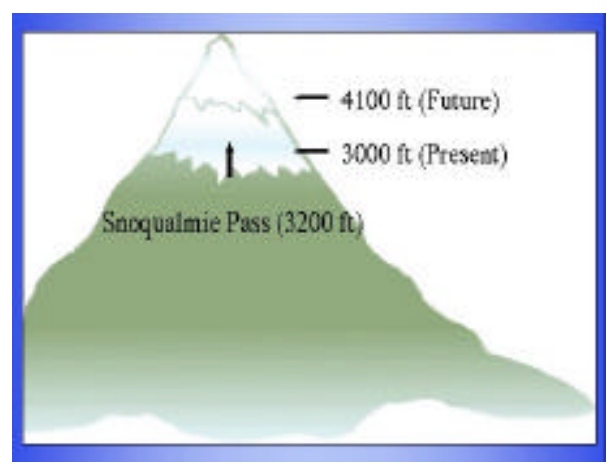

April 1

Columbia

Basin

Snow

Extent

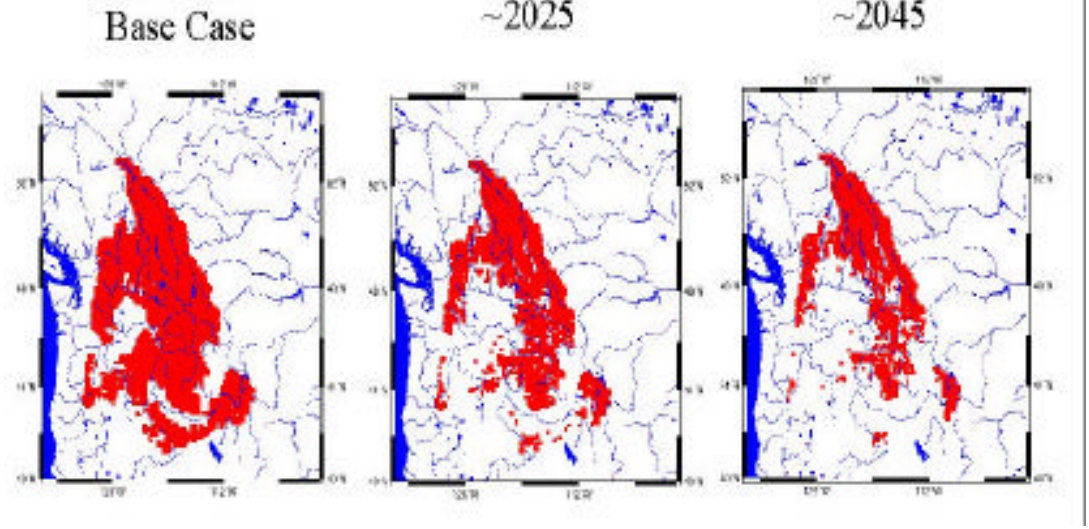

Figure 4: Mean Columbia River basin April 1 snow extent for base case (current climate), 2025, and 2045. (Figure adapted from Hamlet and Lettenmaier, 1999b)

Of the four documents reviewed - Fish and Wildlife Program, Governors' Plan, Biological Opinion, Basinwide Recovery Strategy - only the Biological Opinion explicitly recognizes the effects of climate change on hydrology and water resources. However, this recognition is in the form of a justification for ignoring climate change effects, and assuming that the future will resemble the past (see below). All of the documents deal, in one way or another, with flow and flow augmentation issues in the Columbia mainstem and major tributaries. Hence, even if not explicitly recognized, the use of historical observations to determine effects of altered operations implies an assumption about climate. None of the documents explicitly considers the implications of proposed changes on system performance, particularly in low water years that are the basis for the critical period planning approaches used to determine firm power. A brief summary of relevant comments in the documents follows.

\section{Fish and Wildlife Program}

No mention is made of climate change as it affects riverine ecosystems or water management. There is an implicit assumption underlying statements about reservoir operations that future conditions will resemble the past, for instance, a strategy statement, "Manage the hydrosystem so that patterns of flow more closely approximate the natural hydrographic patterns, and assure any changes in water management are premised upon, and proportionate to, fish and wildlife 
benefits." The "natural hydrographic patterns" in this statement presumably are those that occurred in the pre-development past, not those that would be expected to occur in the future absent development effects. A statement regarding long-term planning that cites the need to revisit flood control requirements and other aspects of water management likewise carries with it an implicit belief that the future climate will resemble that of the past.

\section{Governors' Plan}

Climate is not discussed in the Governors' Plan. With respect to flow management, there are, as in the $2000 \mathrm{FWP}$, implicit assumptions that climate will not change significantly. For instance, the statement "... additional water may be available for flow augmentation if flood control operations can be prudently altered. The Corps and NMFS should work with the region on a study to determine whether flood control rule curves can be reconfigured to allow shaping of flows to improve survival of migrating salmon and steelhead." implies that future water availability will be as in the past.

\section{Basinwide Recovery Strategy}

No mention is made of climate with respect to hydrology and reservoir operations; the only mention of climate has to do with changes in ocean survival of salmon.

\section{Biological Opinion}

The BiOp likewise ignores possible effects of climate change (and/or changes in patterns of variability), but makes this assumption explicit in Chapter 9: "The approach to estimating the outcomes of alternative project operations implies that hydrologic conditions recorded in the past are reasonable estimates of future conditions. The longer the historical period of record used, the more likely the simulation will capture the range of future conditions likely to occur. Although there is growing evidence that the earth's climate is changing, it is unlikely that such changes would substantially violate the assumption that future hydrologic conditions will be similar to past conditions during the 10 years this biological opinion will be in effect". Although this assumption may be defensible with respect to the 10-year time horizon of the BiOp, it fails to recognize that changes in climate (especially effects of shifts in the Pacific Decadal Oscillation, see above, and to a less extent effects of long-term climate change) have already substantially affected historic observations.

Implications of this assumption pervades the document elsewhere, especially in Chapter 3, "Proposed Actions", e.g., "Libby reservoir would be operated throughout fall and winter to achieve a 75\% chance of reaching flood control elevation on April 10"; "Grand Coulee ...would operate during January through April 10 to ensure an 85\% confidence to refill to flood control election" ... All estimates of probabilities are based on historical period of record, which may not be representative. No attempt is made or proposed to account for effects of climate change.

On the other hand, in Chapter 6 of the BiOp ("Effects on habitat in Columbia River mainstem, estuary, and plume: ") it is recognized that "Recent model studies ... indicate that the volume and timing of water and sediment delivery have changed ... even after the effects of climate 
change ... are taken into account." Hence, while there is some recognition of the effects of past climate change on the estuary, and by implication that future changes might occur as well, there is no similar recognition of the effects of climate change on operation of the reservoir system.

\section{Summary}

Do the documents in aggregate represent an adequate response to the problem? Do the documents describe a course of action that is likely to achieve regional goals such as ESA delisting, harvestable fish, and sustainable ecosystems?

The ISAB believes they do not adequately consider climate and hydrology. The issue is basically ignored.

Do the documents in aggregate represent a change in the status quo or a continuation of past efforts?

The ISAB believes the documents do not represent a meaningful change in the status quo. The inherent assumption is that the future will resemble the past. This assumption, which underlies essentially all water resource design and management in the Columbia River Basin and elsewhere, is now being called into question.

Do the documents provide a consistent course of action?

The documents are consistent in that they assume that the future will resemble the past.

Are linkages among strategies for dealing with the 4 H's adequately identified?

The ISAB believes linkages are not adequately identified. Whereas there is some mention in the documents (especially the Basinwide Recovery Strategy) of the role of climate variability and change on ocean survival, it is ignored in the river system.

CRITFC has been investigating alternate operating policies that return the river's flow regime to an approximation of the natural hydrograph (strong spring freshet). This would be done, in part, by altering the flood rule curves to reflect the flow regime in a warmer climate, i.e., more winter flow, less in the spring and summer. The result is that less winter/spring drawdown for flood control is needed, allowing more flow augmentation in the spring and summer. This would represent a departure from existing reservoir operating policy, but is consistent with a "return to the river" philosophy reflecting more normative flows. It is notable that none of the salmon recovery documents explicitly mention possible changes in operation to reflect climatically altered flow regimes.

In general, climate change is likely to represent an additional stress on the system - earlier runoff in the spring, and reduced summer flows, which would generally be detrimental to salmonid survival, unless mitigated by altered reservoir operation. River temperature effects have not been addressed at all. None of the documents addresses the implications of climate change on salmon restoration, and only one (the BiOp) makes the assumption of stable climate explicit with 
respect to its effects on the river system. The Basinwide Recovery Strategy, while recognizing the role of climate (in particular, decadal scale variations) on ocean survival, does not address effects of climate variability and change on survival in the river.

\section{Institutional Arrangements}

In the energy and water appropriations legislation for 1996, adopted November 13, 1995, Congress directed the Northwest Power Planning Council to report to Congress within 180 days "regarding the most appropriate governance structure to allow more effective regional control over efforts to conserve and enhance anadromous and resident fish and wildlife within the Federal Columbia River Power System." As a part of the process designed to meet this charge, the Council convened a workshop on February 1-2, 1996, with participation by individuals representing a diverse set of interests to analyze alternative approaches to the governance of fish and wildlife in the basin. One of the most striking findings of the workshop was:

"The greatest failing in regional governance of fish and wildlife, expressed repeatedly by workshop participants, has been the failure to implement plans. It was generally agreed that actions must be taken if salmon recovery is to be effective. For this to occur, the objectives of plans must be simplified. Those charged with carrying out plans should be accountable for doing so promptly and effectively."

This same concern is evident four years later in our examination of salmon recovery documents. Nowhere in any of these documents is there a clear pathway to implement the processes outlined as necessary for recovery or to attempt to analyze the institutional barriers that may lie in the path of implementation. Indeed, to provide a chance for any of the recovery documents to succeed requires unprecedented cooperation among federal, state, tribal, local agencies and governments, and a variety of non-governmental stakeholders. Simply to assume that this cooperation will be forthcoming, however seems to ignore the history of the Columbia River basin.

\section{Governors' Plan}

The Governors' Plan is organized around the Hs of human activities that influence fish and wildlife survival, but also recognizes what the document calls "the $5^{\text {th }}-\mathrm{H}$, the impact of these actions on humans." While the document is very general in nature and provides few suggestions on how to actually implement suggested changes, it does mirror the concerns of the workshop quoted above and focus on accountability. There are three specific recommendations concerning accountability. They are that the NW Power Planning Council:

1. Prepare an annual accountability report "...to clearly document progress toward meeting fish and wildlife mitigation goals, and how ratepayer money is being spent."

2. Consider shifting contract management "...to a neutral entity."

3. Establish a coordinated information system. 


\section{Basinwide Recovery Strategy}

The Basinwide Recovery Strategy attempts to address specific actions comprehensively and includes a number of processes aimed at facilitating the implementation of the recovery program, including:

- Continue and expand the Federal Caucus

- Establish a habitat team

- Establish a Memorandum of Understanding among federal agencies

- Continue the Regional Forum

- Coordinate harvest and hatchery activities with habitat and hydropower activities

- Coordinate with other regional entities

- Collaborate with others on science

- Initiate recovery planning

- Use performance standards

- Coordinate federal budgets

- Monitor and evaluate progress

The discussion associated with these processes is so general, however, that it provides very little guidance for actual program implementation. The most attention is devoted to the establishment of a Memorandum of Understanding among federal agencies, but the institutional elements that exist within the basin include far more than the federal agencies involved (see below).

\section{Biological Opinion}

The Biological Opinion rejects dam breaching in favor of aggressive tributary habitat improvement, hatchery reform, hydrosystem modifications, and other measures, coupled with a rigorous midpoint review of progress toward restoration goals in 2005 and again in 2008. In section 9.4 Development and Implementation of the 1- and 5-Year Plans, there is a call for more planning. The strategy for implementation is:

"The Action Agencies, coordinating with NMFS and USFWS, shall annually develop 1- and 5 -year plans to implement specific measures in hydro, habitat, hatcheries, harvest, research, monitoring, and evaluation needed to meet and evaluate the performance standards contained in this biological opinion."

This statement is followed by twelve additional points itemizing the need for more planning documents. There are two fundamental assumptions behind this strategy.

1) That the Action Agencies, coordinating with NMFS and USFWS, that to date have had difficulty designing and implementing successful recovery plans, are going to be quickly able to do so now.

2) That the Action Agencies, coordinating with NMFS and USFWS, are the appropriate set of organizations to guide recovery efforts. 
There is mention of input from the tribes or other entities, but the process by which this would be accomplished is unclear.

\section{Fish and Wildlife Program}

The Fish and Wildlife Program addresses all of the Hs, but relies most heavily on mitigating the effects of hydropower operations on fish and wildlife. The program hinges on a broad framework consisting of a vision, scientific principles, biological objectives and strategies laid out at the basin level, with plans to move into planning and implementation at the subbasin level. Implementation primarily focuses on funding projects that support priorities identified in the planning process. While some of the implementation strategies are quite specific, such as the development of a funding agreement for land and water acquisition, the mechanism for how priorities determined in the planning process will result in actions on the ground is unclear.

\section{Summary}

Do the documents in aggregate represent an adequate response to the problem? Do the documents describe a course of action that is likely to achieve regional goals such as ESA delisting, harvestable fish, and sustainable ecosystems?

The ISAB believes the answer to both questions is no. While the documents individually attempt to define the problems and desirable futures states, and in some cases measures of whether those states have been attained, they provide little guidance on how to move from one state to the other. With the exception of the Governors' Plan there is no treatment in any of the documents of the probable trends in human population and economic growth and of the impacts these trends could place on the entire basin ecosystem. In addition, there is almost no discussion of the complex institutional structure existing within the Columbia River Basin and the ways elements of that structure might facilitate, impede, or otherwise interact with planning processes or the implementation of recovery actions. These include:

1. The legal structure surrounding each of the four H's, e.g.

Columbia River Compact

US. v. Oregon

US. v. Washington

Endangered Species Act

Magnuson Act

Pacific Salmon Treaty

2. Organizational stakeholders, e.g.

NMFS

NWPPC

Corps of Engineers

Pacific Fisheries Management Council

Pacific Salmon Commission

Columbia River Inter-Tribal Fish Commission

State, Tribal, and other federal agencies 
3. Public stakeholders, e.g.

Private land owners

The Port of Lewiston

Environmental groups

Various political groups

4. Inter-agency Agreements and Cooperative Agreements

Arrangements to facilitate cooperation and uniform action among organizational stakeholders

5. Mechanisms for Public Input

Public meetings, hearings, etc., to provide for public input

6. The courts

Which, perhaps because of the breakdown of $4 \& 5$, is where recovery decisions are often made

Do the documents in aggregate represent a change in the status quo or a continuation of past efforts?

The documents represent primarily a continuation and evolution of past efforts. While agency plans have grown in detail and complexity, the primary focus is on desired future conditions, largely ignoring the institutional arrangements that have led to the current situation. The strategies also primarily rest on the assumptions that top-down planning, informed by science, can restore productive salmon ecosystems. The Governors' Report challenges this assumption, but presents little evidence that local planning will lead to a dramatic change in the status quo resulting in more effective salmon recovery actions.

Do the documents provide a consistent course of action?

The ISAB believes the documents do not provide a consistent course of action with respect to institutional arrangements. Each of the documents has different goals and was inspired by somewhat different problems. The level of planning, key participants in identifying restoration priorities, and responsibility and monitoring and evaluation, differ among the documents.

Are linkages among strategies for dealing with the 4 H's adequately identified?

The ISAB believes the documents are not adequately linked as they relate to the institutional structures in the Basin. A current view in the Columbia River Basin is that scientific research will ultimately identify and resolve key uncertainties, and that once we have the necessary knowledge, we will be able to make and implement appropriate decisions. There are at least two difficulties with this belief. First, although new knowledge is always desirable and can provide needed insight into critical uncertainties, new knowledge invariably gives rise to new problems and questions, and consequently new uncertainties. In complex and variable systems like the 
Columbia River Basin, ecosystem uncertainty is always high. In effect, while we can advance understanding of salmon ecology, we will always be faced with the requirement for new knowledge to address new uncertainties. Second, even if we had all the necessary knowledge, it is unclear that we have the institutional framework to assimilate that knowledge and use it in appropriate ways to make and successfully implement decisions on recovery.

The region simply may be developing recovery strategies that are consistent with the current institutional framework. There has been little systematic attention devoted to the way in which the various institutional entities within the Basin might be modified to facilitate better implementation of recovery strategies. The exception to this appears to be the workshop conducted by NWPPC and NMFS in January 1996. Unfortunately, although that workshop and the resulting Council report produced some interesting alternative approaches for implementation and dispute resolution, these alternatives do not appear to have been incorporated into the four documents the ISAB examined. 


\section{Literature Cited}

Annear, T. C., and A. L. Conder. 1984. Relative bias of several instream flow methods. North American Journal of Fisheries Management 4:531-539.

Berman, C., and T. P. Quinn. 1991. Behavioral thermoregulation and homing by spring chinook salmon, Oncorhynchus tshawytscha Walbaum, in the Yakima River. Journal of Fish Biology 39:301-312.

Bisbal, G.A. 2001. Conceptual design of monitoring and evaluation plans for fish and wildlife in the Columbia River ecosystem. Environmental Management (In press).

Botkin, D. B., D. L. Peterson, and J. M. Calhoun, technical editors. 2000. The scientific basis for validation monitoring of salmon for conservation and restoration plans.. Olympic Natural Resources Center Technical Report. University of Washington, Olympic Natural resources Center, Forks, Washington, USA. 82 p.

Coutant, C. C. 1998. Turbulent attraction flows for juvenile passage at dams. ORNL/TM-13608, Oak Ridge National Laboratory, Oak Ridge, Tennessee.

Darland, T. J., S. D. Evans, G. L. Rutz, B. J. Hausmann, D. W. Rondorf, and N. S. Adams. 2000. Test of concept to improve fish guidance using induced water currents at Cowlitz Falls Dam, Washington. U. S. Army Corps of Engineers, Walla Walla District, Walla Walla, Washington.

Dunham, J., B. Rieman, and K. Davis. 2001. Sources and magnitude of sampling error in redd counts for bull trout. North American Journal of Fisheries Management 21:343-352.

Federal Caucus (Army Corps of Engineers, Bonneville Power Administration, Bureau of Indian Affairs, Bureau of Land Management, Bureau of Reclamation, Environmental Protection Agency, Fish and Wildlife Service, Forest Service, and National Marine Fisheries Service). 2000. Conservation of Columbia Basin fish. Final basinwide salmon recovery strategy. 3 volumes. Bonneville Power Administration, Portland, Oregon.

Flagg, T. A. and C. E. Nash, editors. 1999. A conceptual framework for conservation hatchery strategies for Pacific salmonids. U.S. Department of Commerce, NOAA Technical Memorandum, NMFS-NWFSC-38. 48p.

Hall, J. D., and N. J. Knight. 1981. Natural variation in abundance of salmonid populations in streams and its implications for design of impact studies. Report EPA-600/S3-81-021, Environmental Protection Agency, Corvallis, Oregon.

Ham, K. D., and T. N. Pearsons. 2000. Can reduced salmonid population abundance be detected in time to limit management impacts? Canadian Journal of Fisheries and Aquatic Sciences 57(1):17-24. 
Hamlet, A.F., Lettenmaier, D.P., 1999a, Columbia River Streamflow Forecasting Based on ENSO and PDO Climate Signals, ASCE Jour. of Water Res. Plan. and Mgmt., 125 (6), pp 333-341, Nov/Dec

Hamlet, A.F., Lettenmaier, D.P., 1999b, Effects of Climate Change on Hydrology and Water Resources in the Columbia River Basin, Am. Water Res. Assoc., 35, (6), pp 1597-1623, Dec

Hard, J. J., R. P. Jones, M. R. Delarm, and R. S. Waples. 1992. Pacific salmon and artificial production under the Endangered Species Act. U.S. Department of Commerce, NOAA Technical Memorandum, NMFS-NWFSC-2. 56p.

Harding, J. S., E. F. Benfield, P. V. Bolstad, G. S. Helfman, and E. B. D. Jones III. 1998. Stream biodiversity: the ghost of land use past. Proceedings of the National Academy of Science 95:14843-14847.

Hatfield, T., and J. Bruce. 2000. Predicting salmonid habitat-flow relationships for streams in western North America. North American Journal of Fisheries Management 20:10051015.

Hilborn, R., and J. Winton. 1993. Learning to enhance salmon production: lessons from the Salmonid Enhancement Program. Canadian Journal of Fisheries and Aquatic Sciences 50:2043-2056.

Holtby, L. B., and J. C. Scrivener. 1989. Observed and simulated effects of climatic variability, clear-cut logging and fishing on the numbers of chum salmon (Oncorhynchus keta) and coho salmon (O. kisutch) returning to Carnation Creek, British Columbia. Pages 62-81 in C.D. Levings, L.B. Holtby, and M.A. Henderson, editors. Proceedings of the national workshop on effects of habitat alterations on salmonid stocks. Canadian Special Publication of Fisheries and Aquatic Sciences 105, Ottawa, Ontario, Canada.

Idaho et al. (Offices of the Governors of Idaho, Montana, Oregon and Washington). 2000. Recommendations of the governors of Idaho, Montana, Oregon and Washington for the protection and restoration of fish in the Columbia River basin.

Independent Scientific Advisory Board (ISAB). 2001. Model synthesis report: an analysis of decision support tools used in Columbia River Basin salmon management. ISAB Report 2001-1, Northwest Power Planning Council, Portland, Oregon.

ISG (Independent Scientific Group). 1996. Return to the River. Northwest Power Planning Council, Portland, Oregon.

ISG. 2000. Return to the River 2000: Restoration of salmonid fishes in the Columbia River Ecosystem. Northwest Power Planning Council, Portland, Oregon.

Johnson, G. E., A. E. Giorgi, and M. W. Erho, Jr. 1997. Critical assessment of surface flow bypass development in the lower Columbia and Snake rivers. U.S. Army Corps of Engineers, Portland and Walla Walla districts, Walla Walla, Washington. 
Kareiva, P., M. Marvier, and M. McClure. 2000. Recovery and management options for spring/summer chinook salmon in the Columbia River Basin. Science 390:977-979.

Kondolf, G. M., E. W. Larsen, and J. G. Williams. 2000. Measuring and modeling the hydraulic environment for assessing instream flows. North American Journal of Fisheries Management 20:1016-1028.

Lichatowich, J., and S. Cramer. 1979. Parameter selection and sample sizes in studies of anadromous salmonids. Information report Series, Fisheries, Number 80-1. Oregon Department of Fish and Wildlife, Portland, Oregon, USA. 25 p.

Mathur, D., W. H. Bason, E. J. Purdy, Jr., and C. A. Silver. 1985. A critique of the Instream Flow Incremental Methodology. Can. J. Fish. Aquat. Sci. 42:825-831.

Maxell, B. A. 1999. A Power analysis on the monitoring of bull trout stocks using redd counts. North American Journal of Fisheries Management 19(3): 860-866.

Mighetto, L., and W. J. Ebel. 1995. Saving the salmon: a history of the U.S. Army Corps of Engineers' efforts to protect anadromous fish on the Columbia and Snake rivers. Historical Research, Inc. Seattle, Washington for the U.S. Army Corps of Engineers, North Pacific division, Portland, Oregon.

Montgomery, D. R. 1995. Input- and output-oriented approaches to implementing ecosystem management. Environmental Management 19(2): 183-188.

NAI (Normandeau Associates, Inc.), J. R. Skalski, and Mid Columbia Consulting, Inc. 2000. Passage survival and condition of chinook smolts through an existing and new minimum gap runner turbines at Bonneville Dam First Powerhouse, Columbia River. (draft) U.S. Army Corps of Engineers, Portland District, Portland, Oregon.

National Research Council (NRC). 1996. Upstream: salmon and society in the Pacific Northwest. National Academy Press, Washington, D.C.

NMFS (U.S. National Marine Fisheries Service, Department of Commerce). 2000. Endangered Species Act - Section 7 consultation. Biological Opinion. Reinitiation of consultation on operation of the Federal Columbia River Power System, including the juvenile fish transportation program, and 19 Bureau of Reclamation projects in the Columbia Basin. Northwest Region, Seattle, Washington.

Odeh, M. 1999. A summary of environmentally friendly turbine design concepts. U.S. Department of Energy, Idaho Operations Office, Idaho Falls, Idaho.

Rieman, B. E. and Myers, D. L. 1997. Use of redd counts to detect trends in bull trout populations. Conservation Biology 11(4):1015-1018. 
Shirvell, C. S. 1989. Habitat models and their predictive capability to infer habitat effects on stock size. Pages 173-179 in C. D. Levings, L. B. Holtby, and M. A. Anderson, editors. Proceedings of the National Workshop on Effects of habitat Alteration on Salmonid Stocks. Canadian Special Publication in Fisheries and Aquatic Sciences 105. 199 p.

Tschaplinski, P. J. 1999. The effects of forest harvesting, fishing, climate variation, and ocean conditions on salmonid populations in Carnation Creek, Vancouver Island, British Columbia. Pages 297-328 In E. E. Knudsen, C. R. Steward, D. D. MacDonald, J. E. Williams, and D. W. Reiser, editors. Sustainable fisheries management: Pacific salmon. Lewis Publishers, New York, N.Y., USA.

USACE (U.S. Army Corps of Engineers). 2000. Anadromous fish evaluation program. 2000 annual research review, November 13-16, 2000. Portland and Walla Walla districts, Portland, Oregon.

Whitney, R. W., L. D. Calvin, M. W. Erho, Jr., and C. C. Coutant. 1997. Downstream passage for salmon at hydroelectric projects in the Columbia River basin: development, installation, and evaluation. Report No. 97-15, Northwest Power Planning Council, Portland, Oregon.

Ziemer, R. 1998. Monitoring watersheds and streams. USDA Forest Service, Pacific Southwest Research Station, General Technical Report PSW GTR-168. 